\title{
The Thermal Effect on the Physical Properties and Corresponding Permeability Evolution of the Heat-Treated Sandstones
}

\author{
Xianshan Liu $\mathbb{D}^{1,2}$ Weiluo Lu, ${ }^{1,2}$ Man Li $\mathbb{D}^{1,2}$ Nandou Zeng, ${ }^{1,2}$ and Tao $\mathrm{Li}^{1,2}$ \\ ${ }^{1}$ Key Laboratory of New Technology for Construction of Cities in Mountain Area (Chongqing University), Ministry of Education, \\ Chongqing 400045, China \\ ${ }^{2}$ School of Civil Engineering, Chongqing University, Chongqing 400045, China
}

Correspondence should be addressed to Xianshan Liu; lzmoumou@163.com and Man Li; 932417390@qq.com

Received 18 September 2020; Revised 5 November 2020; Accepted 6 November 2020; Published 9 December 2020

Academic Editor: Yanlin Zhao

Copyright (C) 2020 Xianshan Liu et al. This is an open access article distributed under the Creative Commons Attribution License, which permits unrestricted use, distribution, and reproduction in any medium, provided the original work is properly cited.

\begin{abstract}
The complex high temperature and high stress are commonly encountered in the hot dry rock for geothermal energy development; the thermal effect on the rock properties and corresponding thermal-hydromechanical coupling process has attracted much more attentions in the field of the energy. Taking the sandstones in Chongqing as a case study, the physical and mechanical experiments of the heat-treated sandstones and corresponding permeability tests under triaxial loading conditions have been widely conducted. It can be seen that the quality, porosity, uniaxial compression strength, and elastic modulus of the heated sandstones vary differently with different heat-treated temperature. As for the permeability tests in the process of gradual failure under triaxial loading conditions, the permeability variation divided by four variation stages is the same as that under room temperature condition, and the initial permeability, minimum permeability, and maximum permeability have been characterized with temperature variation, showing that the permeability variation in a certain temperature range from $400^{\circ} \mathrm{C}$ to $600^{\circ} \mathrm{C}$ presents more obvious than that in other temperature ranges. Furthermore, the relationship between the permeability and the crack volumetric strain of the heat-treated sandstones is further analyzed to prove the mechanism of the permeability evolution. In addition, a damage model has been proposed to deeply determine the correlation of the permeability and damage variables, indicating that gradual damage variation has caused obvious cracks to form flow paths and abruptly change the permeability variation, revealing that the damage can describe the permeability evolution of the heat-treated sandstones considering different temperature and loading conditions.
\end{abstract}

\section{Introduction}

Geothermal energy, as a pollution-free and renewable energy resource, existing in rock masses, has attracted much more attentions in the field of energy; however, the traditional geothermal resources are not enough to meet the energy needs. In recent years, many investigations indicate that most geothermal energy with resources distributed at depths of $3-10 \mathrm{~km}$, which is equivalent to 3081 times the total energy consumption in 2018 in mainland China, is found in hot dry rock to be extracted in the future to solve the energy problem in the world. However, the real hot dry rocks including small pores occur in the environment with high temperature and high stress, especially the high temperature will greatly change the physical properties and corresponding permeability while extracting the heat energy, causing the permeability of hot dry rock is different from that at room temperature and atmospheric pressure. Therefore, the permeability parameters obtained at room temperature cannot be directly used to analyze the deep geothermal engineering [1]. Especially, the permeability is an important index to represent the effect of the geothermal exploration; how to describe the thermal effect on the permeability evolution under strong disturbance conditions should be solved in detail.

In recent years, many researchers have investigated the temperature influencing on the mechanical properties of the rocks. Dwived et al. [2] researched on the physical properties, permeability and crack evolution of the granite in the range of the temperature $30^{\circ} \mathrm{C} \sim 160^{\circ} \mathrm{C}$ and summarized the thermal characteristics; Du et al. [3] conducted the experiments of 
granite after different temperature treatment, indicating that temperature exceeding $400^{\circ} \mathrm{C}$ had obvious influence on the physical properties and mechanical parameters; Su et al. [4] also conducted the uniaxial experiments of the sandstones using heat treatment in the range of $100^{\circ} \mathrm{C} \sim 900^{\circ} \mathrm{C}$, showing that the variation of the wave velocity, uniaxial compression strength, elastic modulus, and ultimate strain greatly changed with increasing temperature; Zhao et al. [5] compared the porosity variation before and after the heat treatment; Zhang et al. [6] researched on the mechanical characteristics of the marble in the range of the room temperature to $800^{\circ} \mathrm{C}$ and also introduced a damage model to describe the marble damage; $\mathrm{Xu}$ et al. [7] deeply investigated the mechanical properties and porosity considering the temperature varying from the room temperature to $1300^{\circ} \mathrm{C}$; Li et al.. [8] researched on the experimental variation of the heat-treated sandstones, discussing the variation of the stress-strain, peak strength, peak strain, and elastic modulus. The above researches indicate that the physical properties, mechanical properties, and corresponding thermal damage are closely related to the temperature; deep investigations should be conducted for the mechanism of the thermal damage and permeability evolution.

Furthermore, the thermal effect on the rock damage and corresponding permeability evolution has also been investigated in recent years. Somerton et al. [9] researched the permeability variation of the rocks considering the temperature treatment; Chen et al. [10] conducted permeability tests related to the damage considering different temperature and thermal rate under compressed conditions, revealing that gradual damage was so obvious to make cracks propagate and enlarged the flow paths with greater permeability; Chaki et al. [11] analyzed the variation of the porosity, permeability to illuminate the thermal damage influencing on the rock properties. Thus, the thermal effect based on the temperature variation is important for investigating the mechanism of the permeability evolution.

Therefore, deep investigations should be done to describe the variation of the physical properties, mechanical properties, and corresponding permeability. And then, the sandstones in Chongqing as a case study, the experiments and theories considering the thermal effect based on temperature variation are further proposed to analyze the damage variation and permeability evolution considering the thermalhydromechanical coupling effect.

\section{Experiments for the Heat-Treated Sandstones}

2.1. Specimen Preparation. For decreasing the sandstone difference and ensuring the accuracy of corresponding tests, the testing sandstones taken from western Xindianzi anticline in Chongqing city are selected for the experiments. According to the method by the International Society for Rock Mechanics (ISRM), the size of all tested sandstone specimens is cylindrical with $50 \mathrm{~mm}$ in diameter and $100 \mathrm{~mm}$ in length approximately. And then, the specimen surface of the sandstones shown in Figure 1(a) has been carefully observed and selected with nonparallelism less than $0.05 \mathrm{~mm}$ and deviation of the axis verticality less than $0.25^{\circ}$. And also, the X-ray Diffractions (XRD) at room temperature indicates that quartz with a content of $66.4 \%$ is mainly inside the sandstone (see Figure 1(b)) and the clay with a content of $16.9 \%$, the calcite with a content of $6.2 \%$, the anorthose with a content of $7.8 \%$, and other minerals with a content of $2.7 \%$. In addition, as shown in Figure 1(b), the intensity maximum of the minerals varies with the temperature variation, it can be observed that the intensity maximum of the quartz is the strongest with the temperature $25^{\circ} \mathrm{C}$, and then the intensity decreases in the range of the temperature $25^{\circ} \mathrm{C} \sim 600^{\circ} \mathrm{C}$, and then the intensity increases considering the temperature greater than $600^{\circ} \mathrm{C}$, illuminating the influence of the temperature variation on the rock minerals.

\subsection{Experimental Design}

2.2.1. The Testing Apparatus. The heated apparatus named high-temperature box resistance furnace (SX2-4-10) was introduced to heat the rocks, including the heating cell with high-resistance $\mathrm{Fe} \mathrm{Cr} \mathrm{Al}$ alloy wire, the thermal insulation materials with lightweight high aluminum insulation brick and aluminum silica fiber composite lining, and the control part with PID intelligent program temperature controller, which has temperature controlling precision of $\pm 1^{\circ} \mathrm{C}$.

All tests will be carried out on a rock servo-controlled triaxial equipment named Rock 600-50HT PLUS manufactured by TOP-INDUSTRIE in France plotted in Figure 2. The system can deal with the constant-head, constant flow-rate, and transient-pulse permeability tests under low or high confining and water pressures, and a high-precision electronic balance is selected to measure the real-time flow rate. The apparatus can be used to deal with hydrostatic pressure tests, conventional triaxial compression tests, triaxial seepage tests, chemical erosion tests, etc. Four kinds of loading modes including displacement loading, stress loading, strain loading, and flow loading are employed during the testing process according to different experimental requirements.

2.2.2. The Experimental Conditions. (1) Divide the specimens into nine groups, and set one group of specimens under room temperature conditions and other eight groups heat-treated by $5^{\circ} \mathrm{C} / \mathrm{min}$ to the setting temperature $100^{\circ} \mathrm{C}, 200^{\circ} \mathrm{C}, 300^{\circ} \mathrm{C}$, $400^{\circ} \mathrm{C}, 500^{\circ} \mathrm{C}, 600^{\circ} \mathrm{C}, 700^{\circ} \mathrm{C}$, and $800^{\circ} \mathrm{C}$, and the specimens are kept in the setting temperature for $2 \mathrm{~h}$ and then cooled the specimens to the room temperature. (2) Measure the properties such as the initial quality, volume, and porosity of every group. (3) Conduct the mechanical tests of the heat-treated sandstones with a loading rate of $0.0005 \mathrm{~mm} / \mathrm{s}$ to obtain corresponding stress and strain.

\subsubsection{The Seepage Tests of the Heat-Treated Sandstones.} As for the seepage tests of the heat-treated sandstones, steady method has been used to measure the rock permeability [12, 13]. For this seepage testing procedure, the permeability of the samples can be calculated by measuring the fluid volume from the pump in a period of time and written by [14],

$$
K=\frac{\mu L V}{A \Delta P \Delta t}
$$




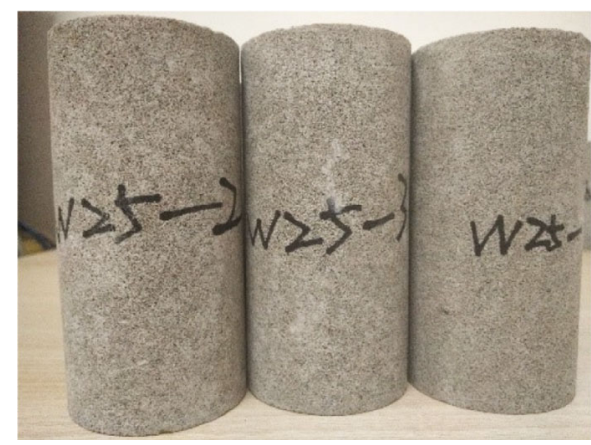

(a) Sandstone specimens
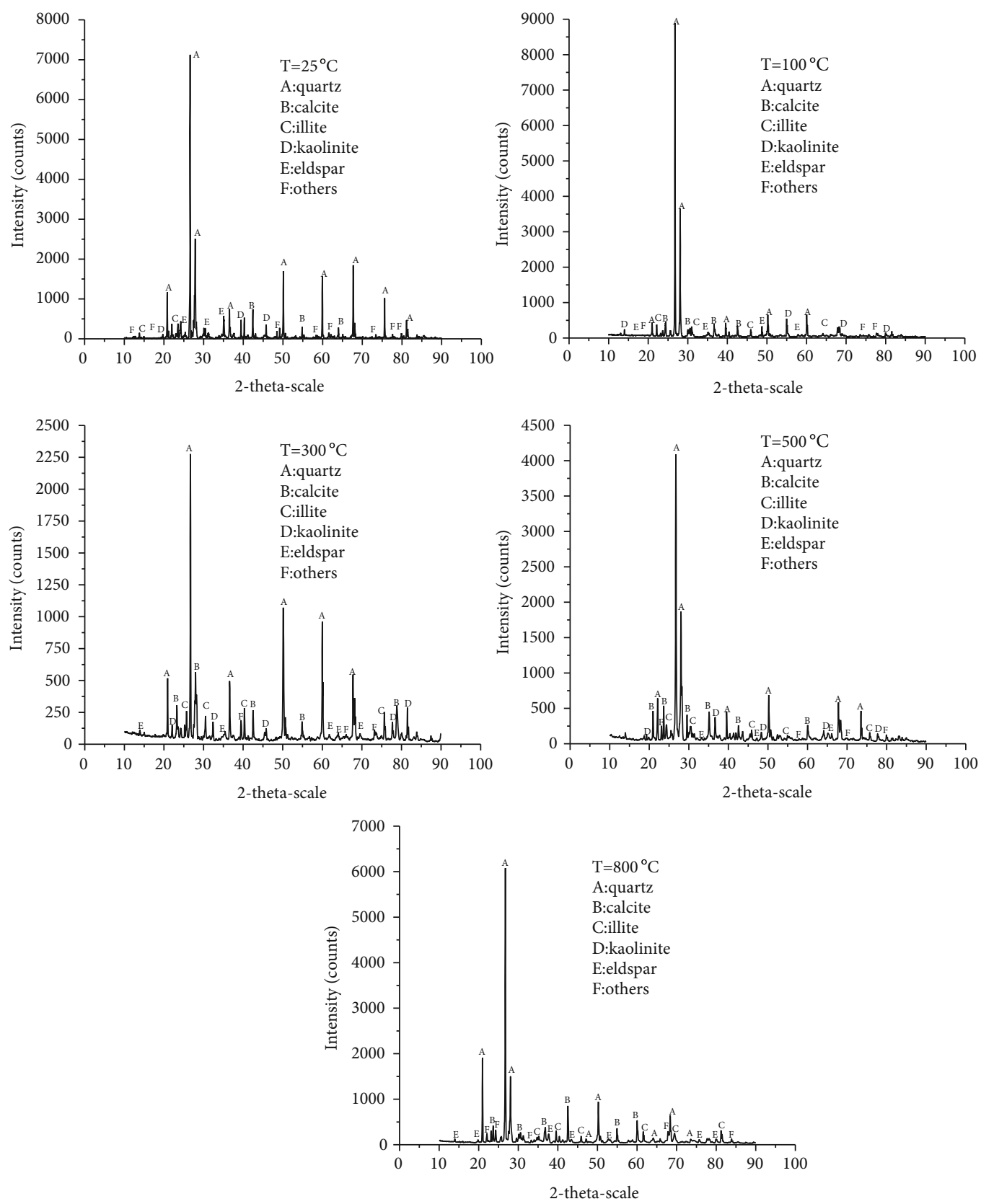

(b) XRD distribution of the sandstone specimens

FIgURE 1: The specimens and corresponding XRD distribution. 


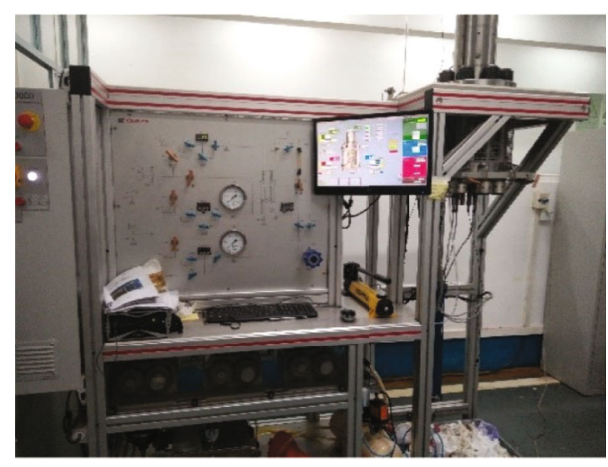

FIGURE 2: Triaxial multiphysics coupling testing system.

Where $K$ is the shale permeability $\left(\mathrm{m}^{2}\right), \mu$ is the fluid dynamic viscosity (water at $T=20^{\circ} \mathrm{C}, 1 \times 10^{-3} \mathrm{~Pa} \cdot \mathrm{s}$ ), $L$ is the shale specimen height $(\mathrm{m}), V$ is the fluid volume $\left(\mathrm{m}^{3}\right)$ from the pump in time $\Delta t, A$ is the crosssectional area $\left(\mathrm{m}^{2}\right), \Delta p$ is the fluid pressure difference $(\mathrm{Pa})$, and $\Delta t$ is the flow time(s).

Before the permeability testing of the heat-treated sandstones, all the specimens should be saturated, vacuumized for $4 \mathrm{~h}$, and dehumidified for $4 \mathrm{~h}$, then immersed into distilled water for $16 \mathrm{~h}$ to fill the rock pores. And then, the saturated specimens are taken into the apparatus and set the confining pressure to the presetting value. Design the testing conditions as follows: (1) confining pressure and permeable pressure are, respectively, set to a certain value, and the axial loading rate is set to $0.0001 \mathrm{~mm} / \mathrm{s}$ until the rocks have been failed. (2) Suppose the confining pressure as $12 \mathrm{MPa}$ and $16 \mathrm{MPa}$ combining the permeable pressure of $2 \mathrm{MPa}$, $3 \mathrm{MPa}, 4 \mathrm{MPa}, 5 \mathrm{MPa}, 6 \mathrm{MPa}$, and $7 \mathrm{MPa}$ to conduct the seepage tests. Furthermore, the testing data are recorded and saved, and the permeability of the heat-treated rocks under different stages can be measured to describe the permeability variation under the designed loading conditions.

\section{Mechanical Analysis of the Heat- Treated Rocks}

\subsection{Variation of the Physical Properties}

3.1.1. The Mass Variation of the Rocks Treated by Different Temperature. Some free water and bound water in the natural rocks may evaporate in the process of the heat treatment and greatly change corresponding physical and mechanical properties. The mass variation of sandstones treated by different temperature has been obtained and plotted in Figure 3, indicating that obvious variation stages is in good agreement with the results by $\mathrm{Hu}$ et al. [14] and Liu and Lei [15]. It is observed from the Figure 3 that variation of the sandstone mass decreases linearly considering the temperature from room temperature $25^{\circ} \mathrm{C}$ to $200^{\circ} \mathrm{C}$ because of more water evaporation in this stage, and then the temperature ascending to $400^{\circ} \mathrm{C}$ while the water evaporating completely, the variation is smooth because of no reaction for the rock minerals; once the temperature rises to $800^{\circ} \mathrm{C}$, the lithofacies is transformed and changed the mineral decomposition, so

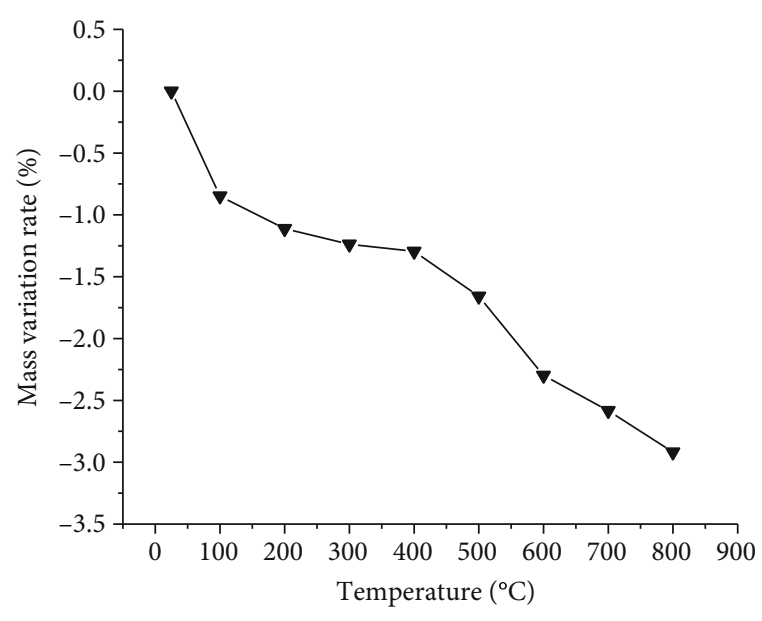

Figure 3: Mass variation rate of the heat-treated sandstone.

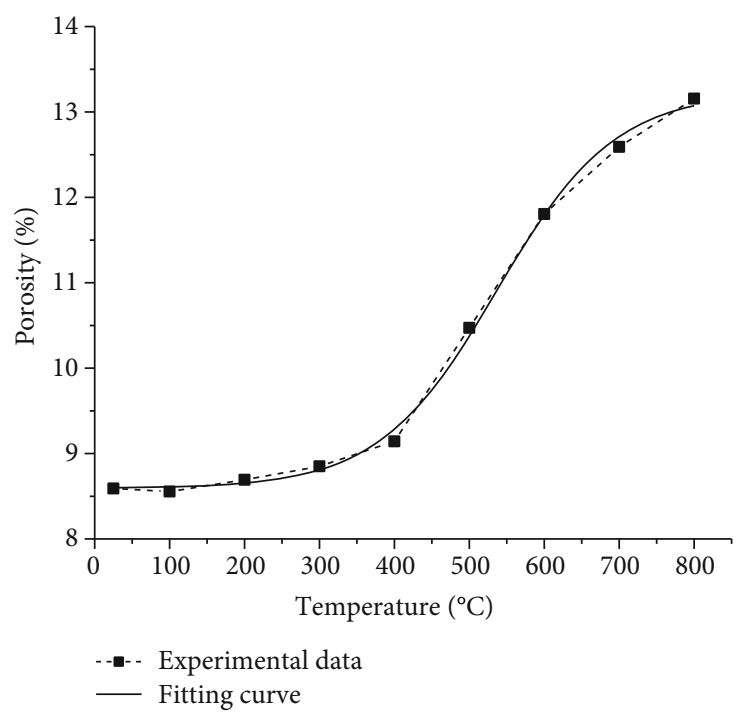

Figure 4: Porosity variation of the heat-treated sandstone.

the mass decreases abruptly in this stage. Therefore, different temperature gives important thermal effect on the physical properties of heat-treated sandstones.

3.1.2. The Porosity Variation of the Rocks Treated by Different Temperature. The porosity variation of the heat-treated sandstones considering different heated temperature [16, 17] is important for determining the water flow paths and corresponding permeability. The porosity variation of rocks treated by different temperature is plotted in Figure 4, indicating that increasing temperature causes the rock minerals open or closure to change the porosity. It can be observed that the porosity increases slowly from $8.64 \%$ with $25^{\circ} \mathrm{C}$ to $9.14 \%$ with $400^{\circ} \mathrm{C}$, while the heated temperature is less than $400^{\circ} \mathrm{C}$; once the heated temperature exceeds $400^{\circ} \mathrm{C}$, the porosity increases abruptly from $9.14 \%$ with $400^{\circ} \mathrm{C}$ to $10.47 \%$ with $500^{\circ} \mathrm{C}$ and even to $13.16 \%$ with $800^{\circ} \mathrm{C}$, which is in good agreement to the results in reference [14]. It can be concluded that smaller heated temperature cannot cause obvious variation of the pores or cracks among the minerals; 


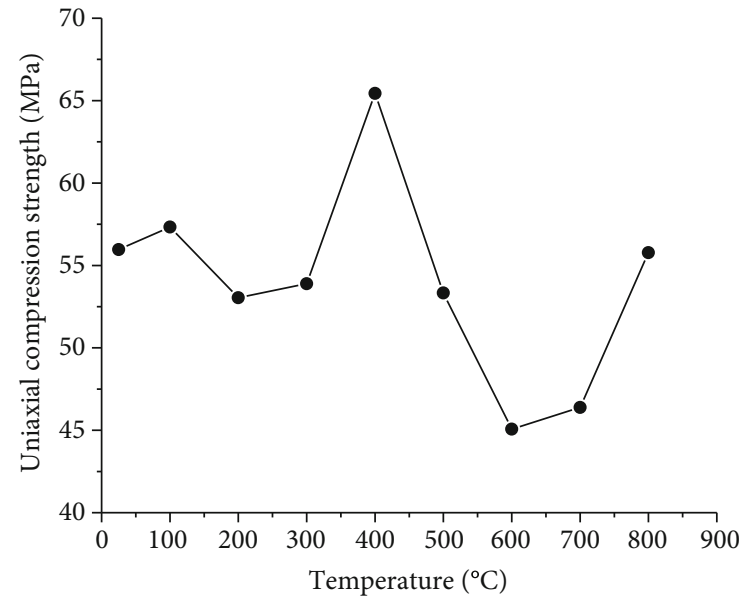

FIGURE 5: Uniaxial compressive strength of heat-treated sandstone.

however, once the heated temperature is greater than a certain temperature, the thermal stress and thermal decomposition cause the pores enlarged abruptly and connected completely, which indicates the thermal effect is greater with increasing temperature. In addition, the expressions based on Boltzmann equation describe the relation of the tested porosity $\varphi$ and temperature $T$ as follows:

$$
\varphi=13.252-4.696 /\left(1+e^{((T-536.305) / 80.666)}\right) .
$$

Where $T_{0}$ is the fitting parameters calculated by the testing data, and the correlation coefficient $R^{2}$ is larger than 0.998 .

\subsection{The Mechanical Variation of the Heat-Treated Sandstone}

3.2.1. The Uniaxial Compressive Strength of the Heat-Treated Sandstone. The uniaxial compressive strength of the heattreated sandstone $[16,17]$ considering different heated temperature is plotted in Figure 5, showing that the strength decreases considering the temperature is less than $200^{\circ} \mathrm{C}$, then increases to the maximum, while the temperature ascends to $400^{\circ} \mathrm{C}$, and then, the strength decreases, while the temperature continues to be $600^{\circ} \mathrm{C}$; finally, the strength increases while the temperature rises to be $800^{\circ} \mathrm{C}$.

3.2.2. The Elastic Modulus of the Heat-Treated Sandstone. The elastic modulus of the heated sandstone considering different heated temperature is plotted in Figure 6, showing that the elastic modulus changes smoothly considering the temperature less than $200^{\circ} \mathrm{C}$, then decreases slowly while the temperature increases to $400^{\circ} \mathrm{C}$, and decreases abruptly while the temperature continues to be $800^{\circ} \mathrm{C}$, indicating that the temperature $400^{\circ} \mathrm{C}$ is the critical temperature for the variation of the elastic modulus. Furthermore, the expression considering the tested elastic modulus $E_{T}$ and temperature $T$ can be written by

$$
E_{T}=4.676+4.178 /\left(1+e^{((T-521.540) / 63.244)}\right) .
$$

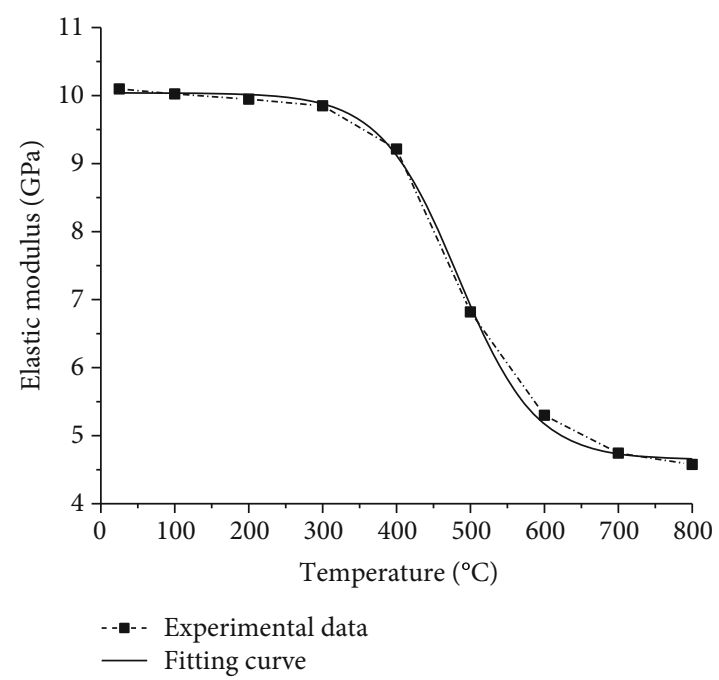

FIGURE 6: Elastic modulus of the heat-treated sandstone.

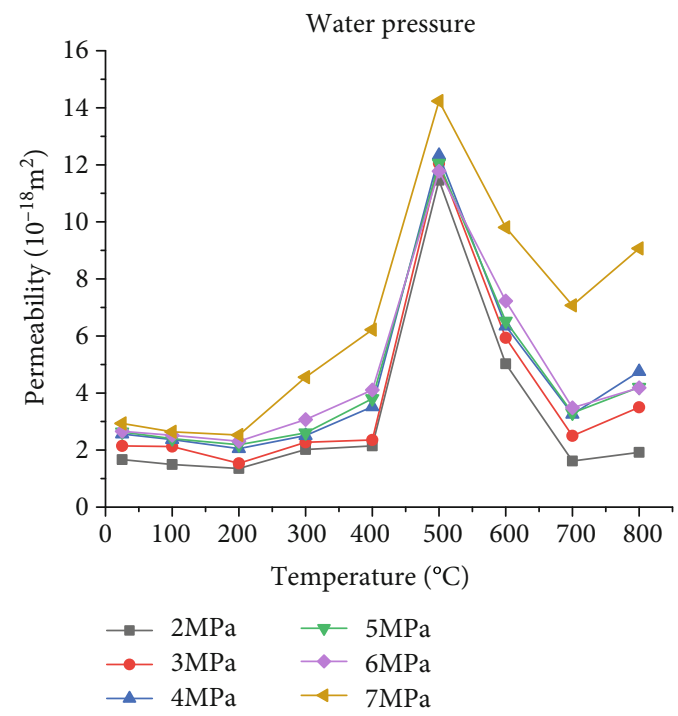

FIGURE 7: Permeability of the sandstones considering axial pressure $10 \mathrm{MPa}$ and confining pressure $12 \mathrm{MPa}$ considering different heated temperature.

Where $E_{T}$ is the elastic modulus of the heated sandstone (GPa), and $T$ is the heated temperature $\left({ }^{\circ} \mathrm{C}\right)$. And the correlation coefficient based on the fitting expression can reached 0.997, indicating this expression can predict the elastic modulus of heat-treated sandstones by different temperature treatment.

\section{The Permeability Variation of the Heat- Treated Sandstones}

4.1. The Testing Permeability of the Heat-Treated Sandstones. For describing the permeability of the heat-treated sandstones, the load combination of the axial pressure, different confining pressure, and different water pressure is considered to apply for the permeability tests, and corresponding testing 
data are plotted in Figures 7 and 8. It can be observed from the Figure 7 considering the axial pressure $10 \mathrm{MPa}$ combining the confining pressure $12 \mathrm{MPa}$ with different water pressure that permeability decreased a bit while the heated temperature increasing from $25^{\circ} \mathrm{C}$ to $200^{\circ} \mathrm{C}$, then increases smoothly from $200^{\circ} \mathrm{C}$ to $400^{\circ} \mathrm{C}$, and increases abruptly from $400^{\circ} \mathrm{C}$ to $500^{\circ} \mathrm{C}$; however, the permeability decreases quickly from $500^{\circ} \mathrm{C}$ to $700^{\circ} \mathrm{C}$; finally, the permeability increases from $700^{\circ} \mathrm{C}$ to $800^{\circ} \mathrm{C}$. Furthermore, the maximum permeability can be concluded as $14.24 \times 10^{-18} \mathrm{~m}^{2}$ considering the temperature $500^{\circ} \mathrm{C}$ and water pressure $7 \mathrm{MPa}$. In addition, the permeability variation of the heat-treated sandstones with axial pressure $10 \mathrm{MPa}$ and confining pressure $16 \mathrm{MPa}$ is plotted in Figure 8. It can be observed from Figure 8 that the permeability variation divided by five stages is similar to the variation in Figure 7, and the maximum permeability valued $13.73 \times 10^{-18} \mathrm{~m}^{2}$ is also under conditions of the temperature $500^{\circ} \mathrm{C}$ and water pressure $7 \mathrm{MPa}$.

Therefore, the permeability of the heat-treated sandstones by different heated temperature even under same loading conditions is different; the main reason is that the heat treatment causes inhomogeneous thermal stress in the sandstones to form new cracks and changes the flow paths, explaining the obvious thermal effect on permeability variation considering different heated temperature.

4.2. The Permeability Variation of the Heat-Treated Sandstones in the Process of the Gradual Failure. The comparison plotted in Figures 7 and 8 shows that the permeability variation of the heat-treated sandstones considering different heated temperature under different water pressure condition. For the sake of better describing the relationship between permeability evolution in the process of the gradual failure under triaxial loading conditions, the variation in Figure 9 shows the permeability evolution considering the confining pressure $30 \mathrm{MPa}$ and water pressure $20 \mathrm{MPa}$, further proving that the thermal effect on the permeability is different for the heat-treated sandstones by different heated temperature [14]. As plotted in Figure 9, it can be observed that the curve of the deviatoric stress and the permeability vs. axial strain can be divided into five stages: (1) compression stage, closure of the existing microcrack and pores results in the crack volumetric strain decreasing to approximately zero, and also the thermal effect causes minerals expanding to block more pores and decrease the permeability. (2) Linear elastic stage, it is observed that the curve of circumferential crack strain vs. deviatoric stress is approximately a straight line, indicating that the thermal stress cannot change the minerals greatly, new cracks cannot appear, and corresponding permeability may be stable. (3) Stable crack propagating stage, more cracks are initiating and propagating when the stress is greater than the crack initiation stress $\sigma_{c i}$. As shown in Figure 9, corresponding stresses $\sigma_{c i}$ for the heat-treated sandstones with different temperature are, respectively, $34.02 \mathrm{MPa}, 35.77 \mathrm{MPa}$, 36.09 MPa, 38.59 MPa, 37.47 MPa, 28.37 MPa, 33.22 MPa, $35.31 \mathrm{MPa}$, and $34.32 \mathrm{MPa}$, which are approximately $28.6 \%$ of corresponding peak stresses, indicating that the extra thermal stress has speeded up the cracks to enlarge the corre-

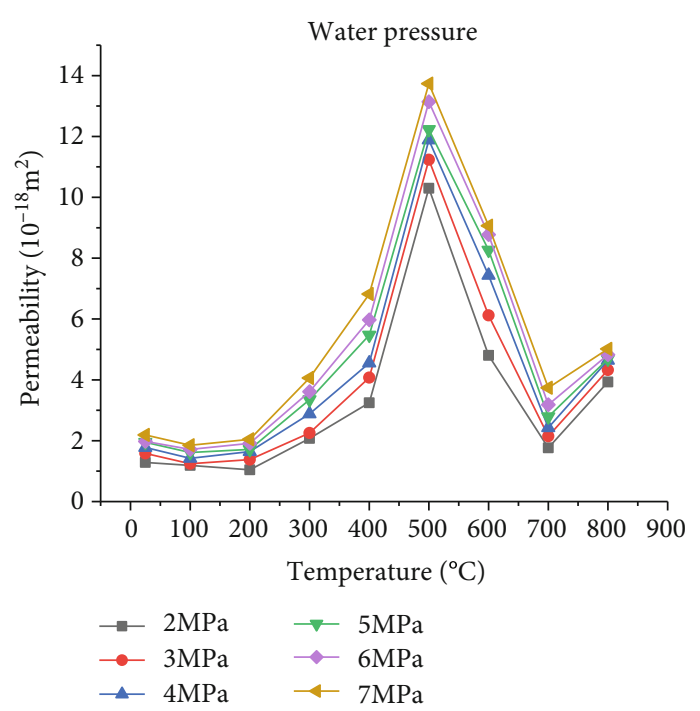

FIgURE 8: Permeability of the sandstones considering axial pressure $10 \mathrm{MPa}$ and confining pressure $16 \mathrm{MPa}$ considering different heated temperature.

sponding volumetric strain to form greater flow paths. (4) Unstable crack developing stage, when the stress is greater than the damage stress $\sigma_{c d}$. As shown in Figure 9, corresponding stresses $\sigma_{c d}$ for the heat-treated sandstones with different temperature are, respectively, obtained by 78.75 MPa， 82.80 MPa， 83.53 MPa， 89.33 MPa， 86.73 MPa, 65.68 MPa, 76.89 MPa, $81.73 \mathrm{MPa}$, and $79.44 \mathrm{MPa}$, which are approximately $66.2 \%$ of peak stresses; thus, the curves of strain vs. deviatoric stress in this stage show strong nonlinearity, especially the crack volumetric stain abruptly increases representing the cracks propagating rapidly and the permeability changing abruptly. (5) Residual deformation stage, macrofractured surface appears with no new cracks initiation and propagation; however, the sliding cracks causing the cracks closure and the bulges disappearance further decrease the permeability.

Also, the permeability evolution curves of the heattreated sandstones under loads combination indicate that the variation patterns of mechanical response and permeability under different confining pressures are similar. However, it can also be observed from the Table 1 that the initial permeability, minimum permeability, and maximum permeability are different for heat-treated sandstones by different heated temperature. It can be seen from the Figures 9-10 and Table 1 that initial permeability under different heated temperature valued $25^{\circ} \mathrm{C}, 100^{\circ} \mathrm{C}, 200^{\circ} \mathrm{C}, 300^{\circ} \mathrm{C}, 400^{\circ} \mathrm{C}, 500^{\circ} \mathrm{C}$, $600^{\circ} \mathrm{C}, 700^{\circ} \mathrm{C}$, and $800^{\circ} \mathrm{C}$ is, respectively, $3.80 \times 10^{-18} \mathrm{~m}^{2}$, $1.74 \times 10^{-18} \mathrm{~m}^{2}, \quad 1.09 \times 10^{-18} \mathrm{~m}^{2}, \quad 1.74 \times 10^{-18} \mathrm{~m}^{2}, \quad 3.34 \times$ $10^{-18} \mathrm{~m}^{2}, 6.10 \times 10^{-18} \mathrm{~m}^{2}, 5.81 \times 10^{-18} \mathrm{~m}^{2}, 3.89 \times 10^{-18} \mathrm{~m}^{2}$, and $4.10 \times 10^{-18} \mathrm{~m}^{2}$, while the loads continuing, the minimum permeability can be obtained as $1.68 \times 10^{-18} \mathrm{~m}^{2}$, $0.85 \times 10^{-18} \mathrm{~m}^{2}, \quad 0.11 \times 10^{-18} \mathrm{~m}^{2}, \quad 0.32 \times 10^{-18} \mathrm{~m}^{2}, \quad 1.93 \times$ $10^{-18} \mathrm{~m}^{2}, 5.14 \times 10^{-18} \mathrm{~m}^{2}, 2.92 \times 10^{-18} \mathrm{~m}^{2}, 0.69 \times 10^{-18} \mathrm{~m}^{2}$, and $0.87 \times 10^{-18} \mathrm{~m}^{2}$ under the heated temperature of $25^{\circ} \mathrm{C}, 100^{\circ} \mathrm{C}, 200^{\circ} \mathrm{C}, 300^{\circ} \mathrm{C}, 400^{\circ} \mathrm{C}, 500^{\circ} \mathrm{C}, 600^{\circ} \mathrm{C}, 700^{\circ} \mathrm{C}$, and $800^{\circ} \mathrm{C}$, which is $0.442,0.489,0.101,0.183,0.578$, 


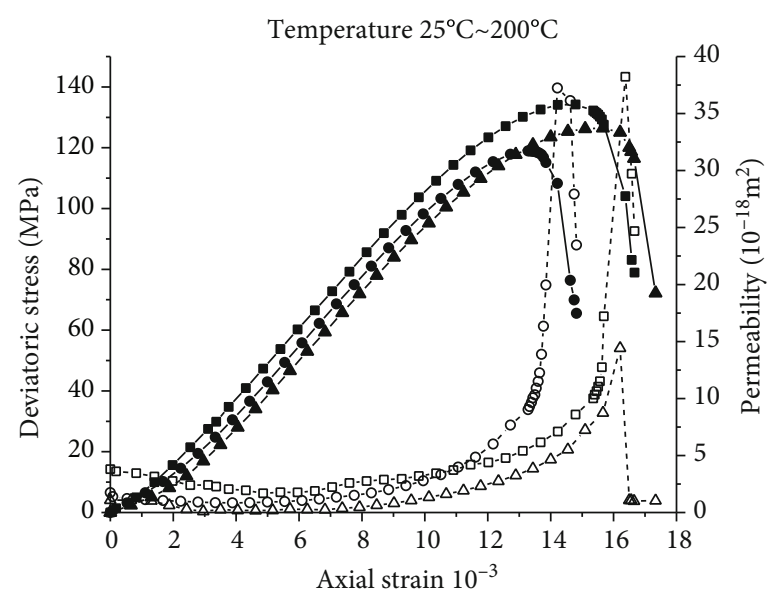

Axial strain vs. deviatoric stress - $-\mathrm{T}=25^{\circ} \mathrm{C}$

-•- $\mathrm{T}=100^{\circ} \mathrm{C}$

- $\boldsymbol{\Delta}$ - $\mathrm{T}=200^{\circ} \mathrm{C}$

Axial strain vs. permeability

- $\square-\mathrm{T}=25^{\circ} \mathrm{C}$

- o- $\mathrm{T}=100^{\circ} \mathrm{C}$

$-\triangle-\mathrm{T}=200^{\circ} \mathrm{C}$

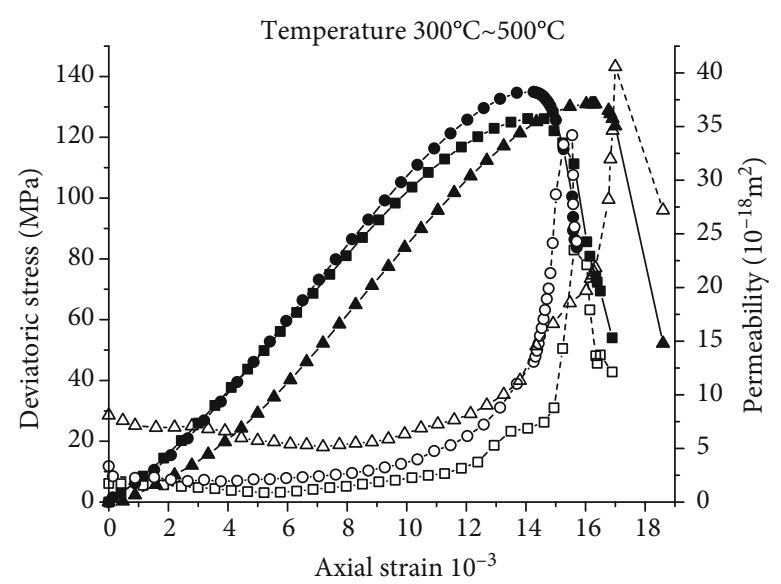

Axial strain vs. deviatoric stress

- $-\mathrm{T}=300^{\circ} \mathrm{C}$

- - $\mathrm{T}=400^{\circ} \mathrm{C}$

- $\boldsymbol{\Delta}-\mathrm{T}=500^{\circ} \mathrm{C}$

Axial strain vs. permeability

- $\square-\mathrm{T}=300^{\circ} \mathrm{C}$

- o- $\mathrm{T}=400^{\circ} \mathrm{C}$

$-\triangle-\mathrm{T}=500^{\circ} \mathrm{C}$

(a) Temperature $25^{\circ} \mathrm{C} \sim 200^{\circ} \mathrm{C}$

(b) Temperature $300^{\circ} \mathrm{C} \sim 500^{\circ} \mathrm{C}$

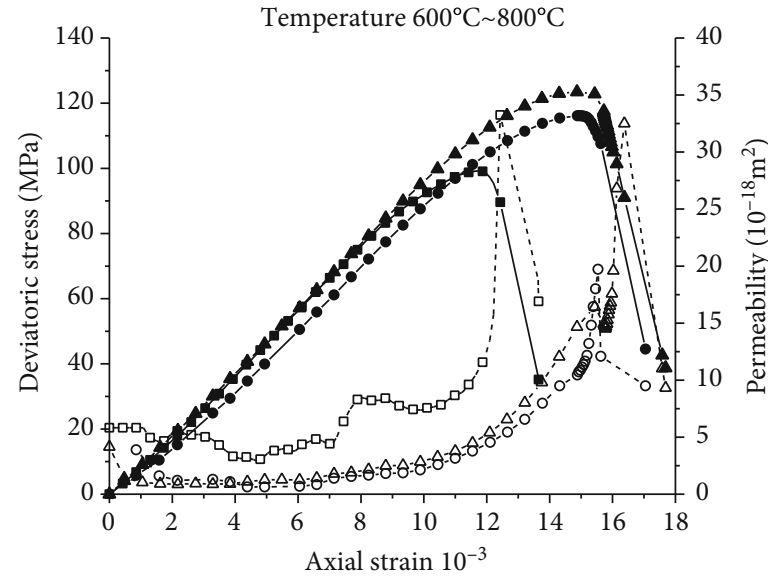

Axial strain vs. deviatoric stress

- $-\mathrm{T}=600^{\circ} \mathrm{C}$

- - $\mathrm{T}=700^{\circ} \mathrm{C}$

- $\boldsymbol{\Delta}$ - $\mathrm{T}=800^{\circ} \mathrm{C}$

Axial strain vs. permeability

- $\square-\mathrm{T}=600^{\circ} \mathrm{C}$

- o- $\mathrm{T}=700^{\circ} \mathrm{C}$

$-\triangle-\mathrm{T}=800^{\circ} \mathrm{C}$

(c) Temperature $600^{\circ} \mathrm{C} \sim 800^{\circ} \mathrm{C}$

FIgURe 9: Permeability evolution of the heat-treated sandstone considering different temperatures.

TABLE 1: Different permeability of the heat-treated sandstones considering different temperature.

\begin{tabular}{lccccccccc}
\hline Temperature $/\left({ }^{\circ} \mathrm{C}\right)$ & 25 & 100 & 200 & 300 & 400 & 500 & 600 & 700 & 800 \\
\hline Initial permeability & 3.8 & 1.74 & 1.09 & 1.74 & 3.34 & 6.10 & 5.81 & 3.89 & 4.10 \\
Minimum permeability & 1.68 & 0.85 & 0.11 & 0.32 & 1.93 & 5.14 & 2.92 & 0.69 & 0.87 \\
Maximum permeability & 38.22 & 37.22 & 14.05 & 23.49 & 34.20 & 40.58 & 33.25 & 32.08 & 32.50 \\
\hline
\end{tabular}




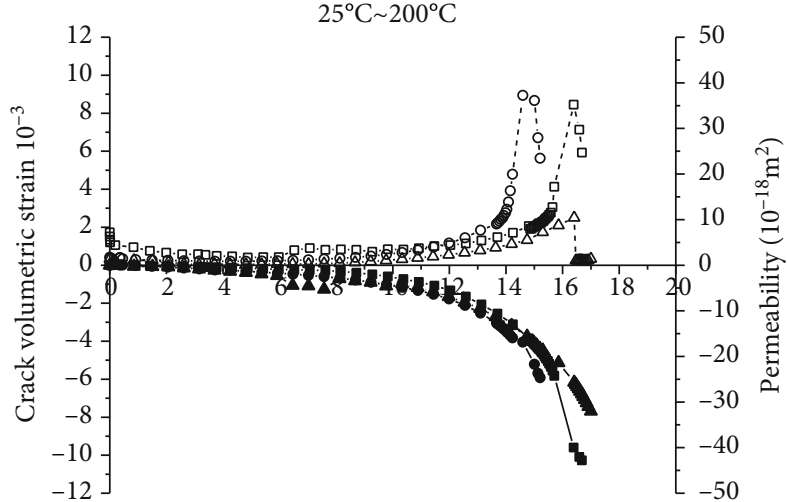

Axial strain $10^{-3}$

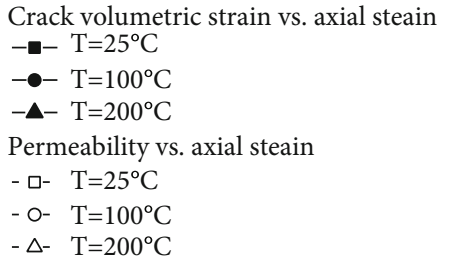

(a) $25^{\circ} \mathrm{C} \sim 200^{\circ} \mathrm{C}$

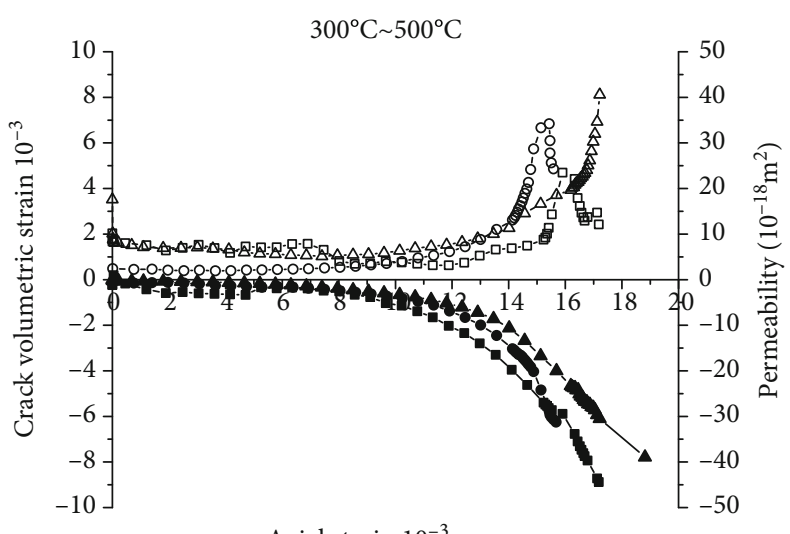

Axial strain $10^{-3}$

(b) $300^{\circ} \mathrm{C} \sim 500^{\circ} \mathrm{C}$

$600^{\circ} \mathrm{C} \sim 800^{\circ} \mathrm{C}$

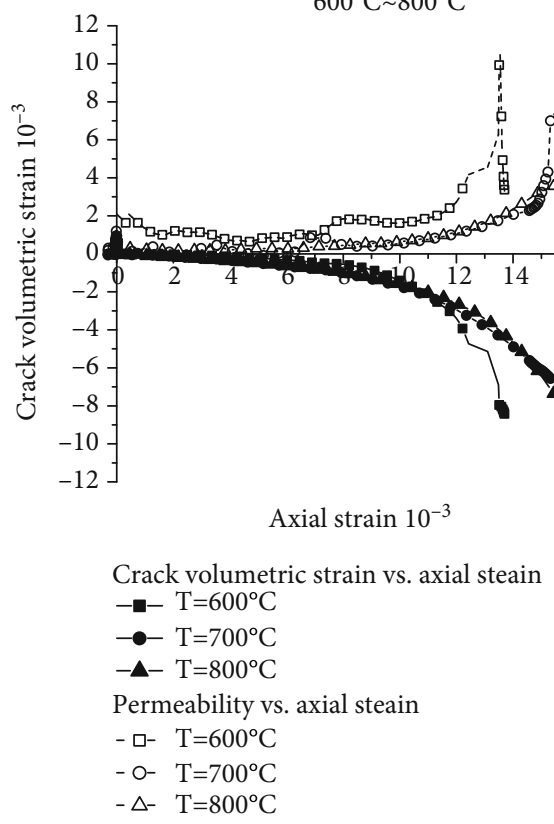

(c) $600^{\circ} \mathrm{C} \sim 800^{\circ} \mathrm{C}$

Figure 10: Permeability and crack volumetric strain variation vs. axial strain of the heat-treated sandstones.

$0.843,0.503,0.177$, and 0.212 times of the initial permeability under the same loading conditions. Once the loads increase to cause the rock damage more obviously, the propagated cracks are connected to form large flow paths; thus, corresponding maximum permeability may be obtained as $38.22 \times 10^{-18} \mathrm{~m}^{2}, \quad 37.2 \times 10^{-18} \mathrm{~m}^{2}, \quad 14.05 \times 10^{-18} \mathrm{~m}^{2}$, $23.49 \times 10^{-18} \mathrm{~m}^{2}, 34.20 \times 10^{-18} \mathrm{~m}^{2}, 40.58 \times 10^{-18} \mathrm{~m}^{2}, 33.25$ $\times 10^{-18} \mathrm{~m}^{2}, 32.08 \times 10^{-18} \mathrm{~m}^{2}$, and $32.50 \times 10^{-18} \mathrm{~m}^{2}$ under the heated temperature of $25^{\circ} \mathrm{C}, 100^{\circ} \mathrm{C}, 200^{\circ} \mathrm{C}, 300^{\circ} \mathrm{C}$, $400^{\circ} \mathrm{C}, 500^{\circ} \mathrm{C}, 600^{\circ} \mathrm{C}, 700^{\circ} \mathrm{C}$, and $800^{\circ} \mathrm{C}$.
4.3. The Permeability Variation of the Heat-Treated Sandstones Based on Crack Volumetric Strain. The above figures describe the permeability variation of the heattreated sandstones by different heated temperature. For better presenting the permeability variation in the process of gradual damage under triaxial loading conditions, the crack volumetric strain proposed by Martin and Chandler [18] has been introduced to describe the crack initiation and propagation and corresponding permeability characteristics. Thus, the volume strain $\varepsilon_{v}$ and the crack 


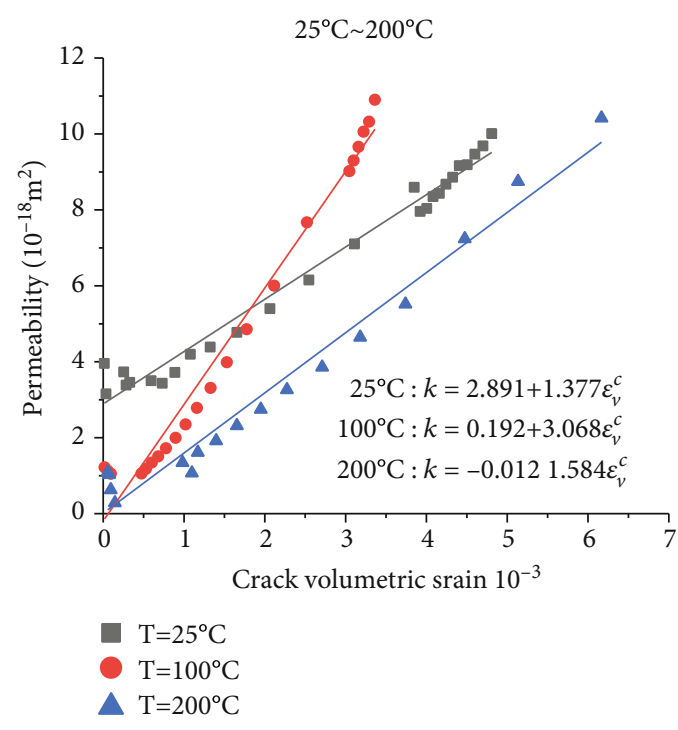

(a) $25^{\circ} \mathrm{C} \sim 200^{\circ} \mathrm{C}$

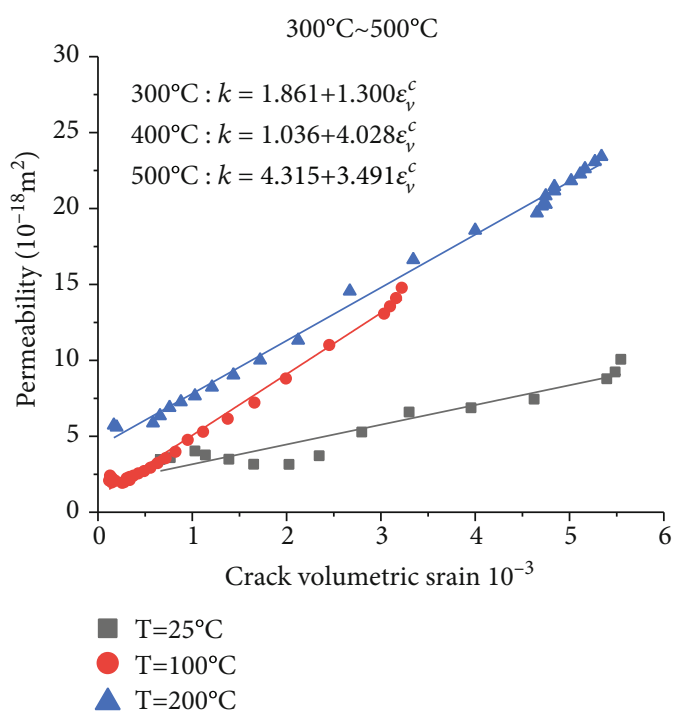

(b) $300^{\circ} \mathrm{C} \sim 500^{\circ} \mathrm{C}$

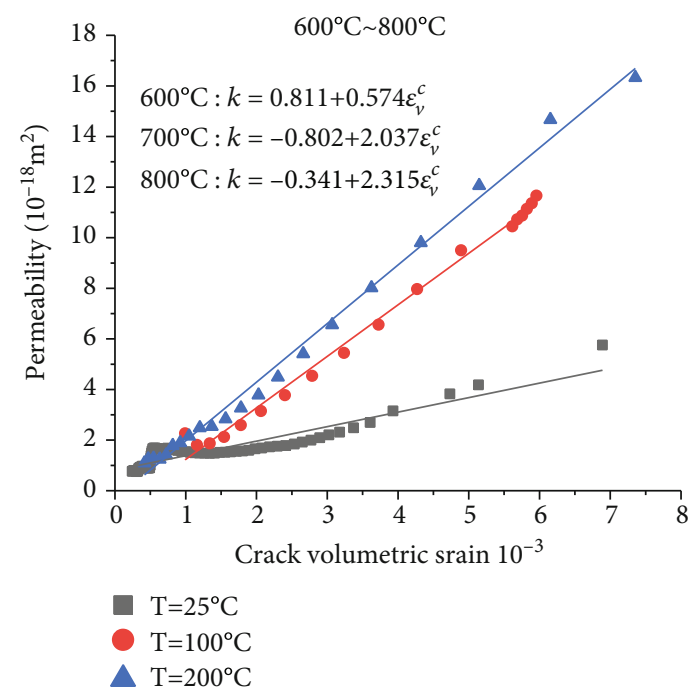

(c) $600^{\circ} \mathrm{C} \sim 800^{\circ} \mathrm{C}$

FIGURE 11: Curves of the crack volumetric strain and permeability considering different heated temperature.

volumetric strain $\varepsilon_{c v}$ under triaxial compression conditions can be written by

$$
\begin{aligned}
& \varepsilon_{v}=\varepsilon_{1}+2 \varepsilon_{3} \\
& \varepsilon_{\mathrm{v}}^{\mathrm{c}}=\varepsilon_{\mathrm{v}}-\frac{1-2 \mu}{E_{T}}\left(\sigma_{1}+\sigma_{2}+\sigma_{3}\right) .
\end{aligned}
$$

Where $\varepsilon_{1}$ and $\varepsilon_{3}$ are the axial strain and lateral strain, respectively; $\varepsilon_{v}$ is the volumetric strain; $\varepsilon_{\mathrm{v}}^{\mathrm{c}}$ is the crack volumetric strain; $E_{T}$ and $\mu$ are, respectively, the elastic modulus and Poisson's ratio of the heat-treated sandstones; and $\sigma_{1}, \sigma_{2}$, and $\sigma_{3}$ are principle stresses.

The relationship of the permeability and the crack volumetric strain under triaxial loading conditions has been calculated and plotted in Figure 10. It can be observed that the permeability evolution is close to the variation of the crack volumetric strain, showing that in the initial loading stage, cracks in the first stage is greatly compacted causing the permeability and crack volumetric strain decreasing, and in the elastic stage, the permeability and crack volumetric strain keep stable; once the crack volumetric strain increases abruptly, the permeability increases more quickly. For better describing the relationship of the permeability and corresponding crack volumetric strain of the heated sandstones by different temperature, Figure 11 has given the curves indicating that propagation of the cracks enlarges greater crack volumetric strain, resulting in the permeability increase. Furthermore, it can be compared from the two curves in Figure 11; the permeability is closely related to the crack volumetric strain, indicating the crack volumetric strain can represent the development of the flow paths and reveal the permeability evolution in the whole damage process. 


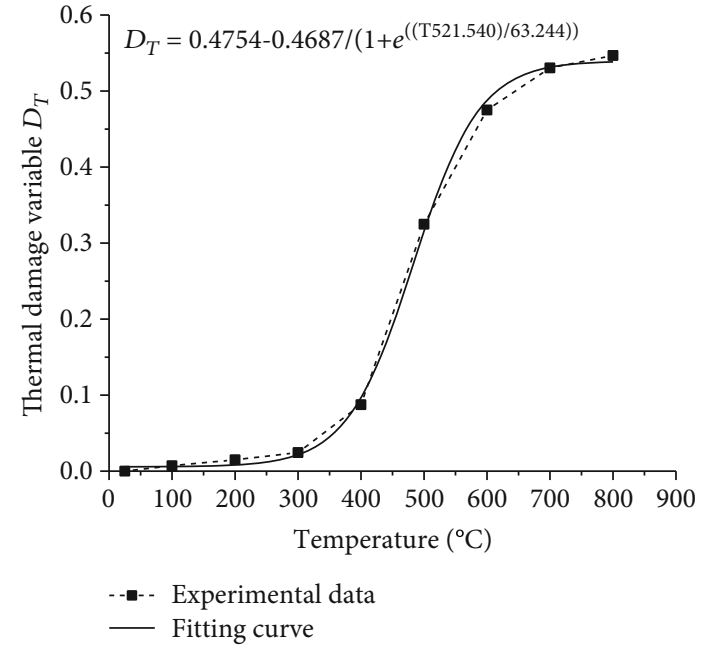

FIGURE 12: Thermal damage variables of the heat-treated sandstone by different heated temperature.

\section{The Evolution Mechanism of the Permeability of the Heat-Treated Sandstones}

5.1. The Damage Characteristics of the Heat-Treated Sandstone considering the Thermal Effect. As we all know, rock cracks will initiate and generate under thermal conditions, resulting in the variation of the mechanical properties of the heat-treated rocks; thus, the thermal damage should be considered and corresponding damage variable [19] may be proposed as follows:

$$
D_{T}=1-\frac{E_{T}}{E_{0}}
$$

Where $E_{T}$ and $E_{0}$ are, respectively, the elastic modulus in temperature $T$ and room temperature. Therefore, the damage considering different heated temperature can be calculated as plotted in Figure 12, showing that the damage increases with larger temperature and can be fitted by the following expressions $D_{T}=0.4754-0.4687 /(1+$ $\left.e^{((T-521.540) / 63.244)}\right)$.

Furthermore, the relationship between the permeability and the thermal damage has been investigated for the sandstones treated by different heated temperature; thus, the curves of the permeability and thermal damage considering the axial pressure $10 \mathrm{MPa}$ and confine pressure with $12 \mathrm{MPa}$ and $16 \mathrm{MPa}$ have been compared. It can be seen from the Figure 13 that the thermal damage is very small considering the temperature is less than $200^{\circ} \mathrm{C}$; however, the permeability decrease is very obvious considering different water pressure; once the heated temperature is in the range of $200^{\circ} \mathrm{C} \sim 500^{\circ} \mathrm{C}$, the thermal damage increases abruptly causing the permeability increasing greatly under different water pressure conditions, and while the heated temperature rises in the range of $500^{\circ} \mathrm{C} \sim 700^{\circ} \mathrm{C}$, the thermal damage increasing gradually causes permeability decrease; however, the permeability increases with the thermal damage increases in the range of $700^{\circ} \mathrm{C} \sim 800^{\circ} \mathrm{C}$, which is in good agreement with the above results. Therefore, the permeability characteristics considering different heated temperature is different because of sandstones structures variation in the range of the heated temperature $25^{\circ} \mathrm{C} \sim 800^{\circ} \mathrm{C}$; explaining the permeability considering different heated temperature is closely related to the thermal effect.

\subsection{The Model of the Permeability considering the Thermal-} Hydromechanical Coupling Effect

5.2.1. The Damage Theory. As evidenced by the experimental results mentioned above, microcracks tend to propagate causing obvious damage inside the sandstones under loading conditions, which induces significant variation in permeability [20]. To deeply characterize the permeability change of the heat-related sandstones, an important index named damage variable $D$ describing the defects variation closely related to the microcrack growth and microstructural evolution should be proposed. Thus, it is assumed that the strength of rock microelements obeys Weibull stochastic distribution; accordingly, the damage variable $D$ can be described by

$$
\begin{aligned}
D & =\frac{V_{\mathrm{P}}}{V}=\frac{\iiint_{V} \int_{0}^{k} f(k) \mathrm{d} k \mathrm{~d} x \mathrm{~d} y \mathrm{~d} z}{V} \\
& =\frac{V \int_{0}^{k} f(k) \mathrm{d} k}{V}=\int_{0}^{k} f(k) \mathrm{d} k .
\end{aligned}
$$

Where $f(k)=\left\{\begin{array}{ll}(m / F)(k / F)^{m-1} \exp \left\{-\left[(k / F)^{m}\right]\right\} & (k \in[0, \infty)) \\ 0 & (k \in(-\infty, 0))\end{array}\right.$, $F(k)=1-\exp \left\{-\left[(k / F)^{m}\right]\right\}(k \in[0, \infty)), m$, and $F_{0}$ are the Weibull parameters; $F$ is the random strength variables of rock microelements; $V_{p}$ is the damage volume; $V$ is the whole volume of all elements; $n$ is number of the failed elements; and $N$ is the number of all elements.

In which, the Weibull parameters are supposed to be the functions of temperature

$$
\left.\begin{array}{l}
m(T)=m_{0}\left(1-D_{T}\right) \\
F(T)=F_{0}\left(1-D_{T}\right)
\end{array}\right\}
$$

And the Drucker-Prager criterion is introduced to be the failure criterion written by

$$
f[[\sigma])=k=\alpha_{0} I_{1}+\sqrt{J_{2}}=\frac{\sin \varphi}{\sqrt{9+3 \sin ^{2} \varphi}} I_{1}+\sqrt{J_{2}} .
$$

Where $I_{1}$ is first invariant of effective stress tensor expressed by Eq. (8), and $J_{2}$ is second invariant of effective stress tensor by Eq. (10); thus, the damage variable $D$ can be written by Eq. (11),

$$
I_{1}=\sigma_{1}^{*}+\sigma_{2}^{*}+\sigma_{3}^{*}
$$




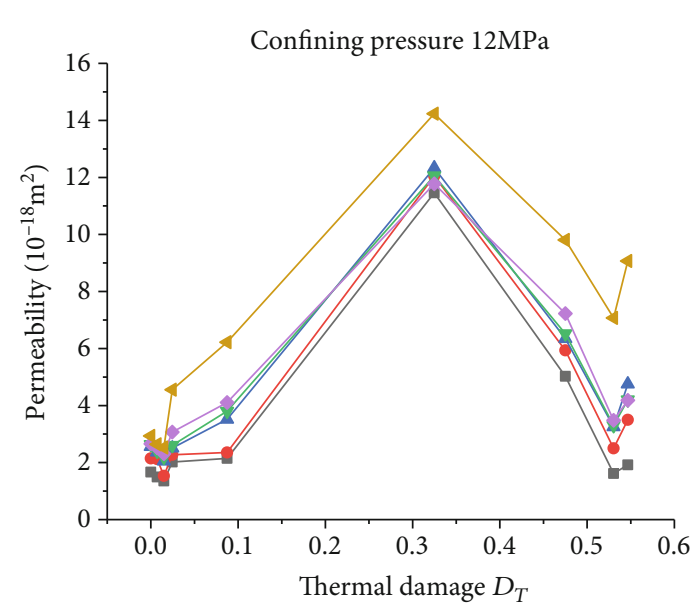

(a) Confining pressure $12 \mathrm{MPa}$

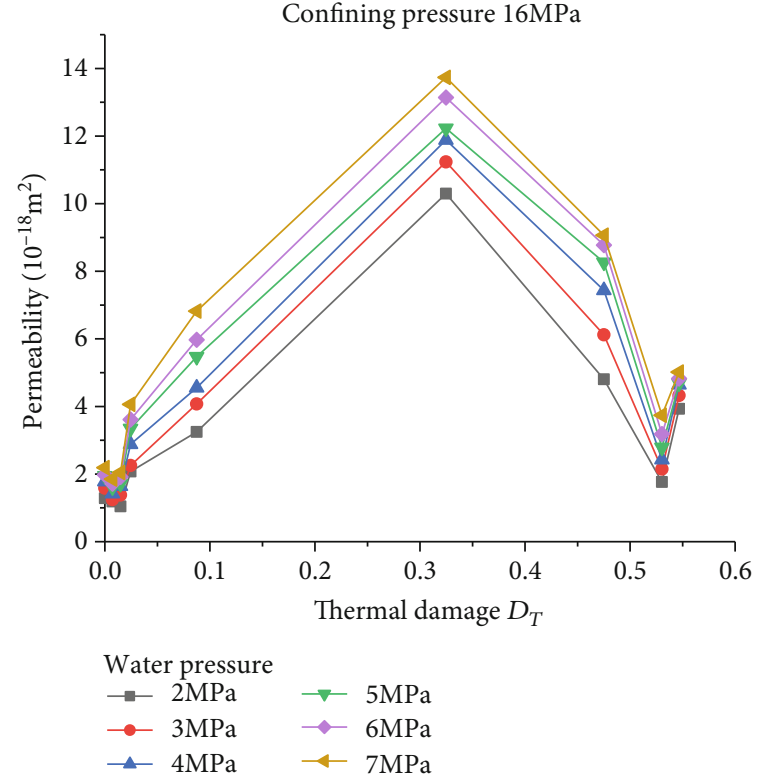

(b) Confining pressure $16 \mathrm{MPa}$

FIGURE 13: Comparison of the permeability and the thermal damage variable.

$$
\begin{aligned}
& J_{2}=\frac{1}{6}\left[\left(\sigma_{1}^{*}-\sigma_{2}^{*}\right)^{2}+\left(\sigma_{2}^{*}-\sigma_{3}^{*}\right)^{2}+\left(\sigma_{3}^{*}-\sigma_{1}^{*}\right)^{2}\right], \\
& D=1-\exp \left[-\left(\frac{\alpha_{0} I_{1}+\sqrt{J_{2}}}{F}\right)^{m}\right] .
\end{aligned}
$$

Furthermore, the damage occurs under a critical stress conditions; thus, the damage variable should be written by

$D(\sigma, T)=\left\{\begin{array}{ll}D_{T} & \left(\sigma<\sigma_{D i}\right) \\ 1-\exp \left\{-\left[\frac{\alpha_{0} I_{1}+\sqrt{J_{2}}}{F_{0}\left(1-D_{T}\right)}\right]^{m_{0}\left(1-D_{T}\right)}\right\} & \left(\sigma \geqslant \sigma_{D i}\right)\end{array}\right.$.

Where $D(\sigma, T)$ is the damage variable considering the heated temperature, and $\sigma_{D i}$ is the crack initiated stress of the heat-treated sandstones.

5.2.2. The Constitutive Model considering the Thermal-FluidMechanical Coupling Effect. Based on Lemaitre's theory [21] and the researches [22-27], and considering the influence of the residual strength on the rock damage, a correction coefficient $\delta=\sqrt{\sigma_{r} / \sigma_{c}}\left(\sigma_{r}\right.$ is the residual stress; $\sigma_{c}$ is the peak stress) in the range of $0 \sim 1$ is proposed to correct the damage variable $D$, so the total stress $\sigma$ and the effective stress $\sigma^{*}$ can be expressed by

$$
\begin{aligned}
{\left[\sigma^{*}\right] } & =\frac{[\sigma]-[\zeta] p_{w}}{1-\delta[D]} \\
\sigma_{i}^{*} & =\frac{\sigma_{i}-p_{w}}{1-\delta D} \quad(i=1,2,3) .
\end{aligned}
$$

Where $[\sigma]$ is matrix of the total stress, $\left[\sigma^{*}\right]$ is the matrix of the effective stress, $[\varepsilon]$ is the strain matrix, $[D]$ is the damage matrix, $p_{w}$ is the water pressure, and $[\zeta]$ is the Kronecker sign.

And suppose the stress-strain of the sandstones obeying the generalized Hook's Law, the effective strain tensor can be written by

$$
\begin{aligned}
\varepsilon_{i}= & \frac{1}{E(1-\delta[D])}\left[\sigma_{i}-\mu\left(\sigma_{j}+\sigma_{k}\right)+(2 \mu-1) p_{w}\right] \\
\varepsilon_{i}= & \frac{1}{E}\left[\sigma_{i}^{*}-\mu\left(\sigma_{j}^{*}+\sigma_{k}^{*}\right)\right] \\
& (i, j, k=1,2,3) .
\end{aligned}
$$

Therefore, as for the stress before reaching the critical damage, it can be expressed by quadratic function through the origin points $(0,0)$, and as for the stress once exceeding the critical damage, the Eq. (11) and Eq. (5) can be substituted into the above formula (14); a new constitutive expression considering the critical damage is written as follows:

$$
\sigma_{i}=\left\{\begin{array}{l}
A \varepsilon_{i}^{2}+B \varepsilon_{i}\left(0 \leqslant \varepsilon_{i} \leqslant \varepsilon_{D i}\right) \\
E_{0}\left(1-D_{T}\right) \varepsilon_{i}\left\{1-\delta+\delta \exp \left\{-\left\{\left[\frac{\alpha_{0} I_{1}+\sqrt{J_{2}}}{F_{0}\left(1-D_{T}\right)}\right]^{m_{0}\left(1-D_{T}\right)}\right\}\right\} .\right. \\
+\mu\left(\sigma_{j}+\sigma_{k}\right)+(1-2 \mu) p_{w}\left(\varepsilon_{i}>\varepsilon_{D i}\right)
\end{array}\right.
$$

Where $\varepsilon_{D i}$ is the strain corresponding to the critical damage.

In addition, considering the principle stress-stain $\varepsilon_{1}^{*}=$ $(1 / E)\left[\sigma_{1}^{*}-\mu\left(\sigma_{2}^{*}+\sigma_{3}^{*}\right)\right]$ and $\sigma_{1}>\sigma_{2}=\sigma_{3}$ and $\varepsilon_{1}=\varepsilon_{1}^{*}$ in 
triaxial tests, the Drucker-Prager failure criterion under thermal-hydromechanical coupling conditions can be written by

$$
\begin{aligned}
f[[\sigma])= & k=\frac{\sin \varphi}{\sqrt{9+3 \sin ^{2} \varphi}} \frac{\left(\sigma_{1}+2 \sigma_{3}-3 p_{w}\right) E \varepsilon_{1}}{\sigma_{1}-2 \mu \sigma_{3}+(2 \mu-1) p_{w}} \\
& +\frac{\left(\sigma_{1}-\sigma_{3}\right) E \varepsilon_{1}}{\sqrt{3}\left(\sigma_{1}-2 \mu \sigma_{3}+(2 \mu-1) p_{w}\right)} .
\end{aligned}
$$

Therefore, the relationship of the stress and strain of the heat-treated sandstone under hydromechanical coupling conditions can be expressed by

$$
\sigma_{1}=E_{0} \varepsilon_{1}(1-D)+2 \mu \sigma_{3}+(1-2 \mu) p_{w} \text {. }
$$

In addition, the measured axial deviatoric stress can be written by $\sigma_{1 t}=\sigma_{1}-\sigma_{3}$, and the real axial stain $\varepsilon_{1}$ should include the measured stain $\varepsilon_{1 t}$ and initial stain $\varepsilon_{10}$ shown as following formula (18).

$$
\begin{aligned}
\varepsilon_{1} & =\varepsilon_{10}+\varepsilon_{1 t} \\
\varepsilon_{10} & =\frac{1-2 \mu}{E_{T}}\left(\sigma_{3}-p_{w}\right) .
\end{aligned}
$$

Therefore, a simplified constitutive model based on real experiments is written by

$$
\sigma_{1 t}=\left\{\begin{array}{l}
A \varepsilon_{1 t}^{2}+B \varepsilon_{1 t}\left(0 \leqslant \varepsilon_{1 t} \leqslant \varepsilon_{D}\right) \\
H_{1}\left\{1-\delta+\delta \exp \left\{-\left[\left(\frac{k}{F}\right)^{m}\right]\right\}\right. \\
+(2 \mu-1)\left(\sigma_{3}-p_{w}\right)\left(\varepsilon_{1 t}>\varepsilon_{D}\right)
\end{array}\right.
$$

In which, $H_{1}=E_{T} \varepsilon_{1 t}+(1-2 \mu)\left(\sigma_{3}-p_{w}\right) ; \quad k=(\sin \varphi /$ $\left.\sqrt{9+3 \sin ^{2} \varphi}\right)\left(\left(\sigma_{1 t}+3 \sigma_{3}-3 p_{w}\right) H_{1} / \sigma_{1 t}+(1-2 \mu)\left(\sigma_{3}-p_{w}\right)\right)$ $+\left(\sigma_{1 t} H_{1} / \sqrt{3}\left[\sigma_{1 t}+(1-2 \mu)\left(\sigma_{3}-p_{w}\right)\right]\right)$; and the parameters $E_{T}, \mu, \varphi$, and $\delta$ can be obtained by the experiments. And for determining the Weibull parameters, the peak point method $[23,24]$ is introduced to deal with the statistical parameters; thus, the expression in point $\left(\sigma_{1 p}, \varepsilon_{1 p}\right)$ can be written by

$$
\sigma_{1 p}=H_{2}\left\{1-\delta+\delta \exp \left[-\left(\frac{k}{F}\right)^{m}\right]+(2 \mu-1)\left(\sigma_{3}-p_{w}\right)\right.
$$

In which, $H_{2}=E_{T} \varepsilon_{1 p}+(1-2 \mu)\left(\sigma_{3}-p_{w}\right)$,

$$
\begin{aligned}
\left.\frac{\partial \sigma_{1 t}}{\partial \varepsilon_{1 t}}\right|_{\varepsilon_{1 p}}= & E_{T}\left\{1-\delta+\delta \exp \left[-\left(\frac{k}{F}\right)^{m}\right]\right\} \\
& +H_{2} \exp \left[-\left(\frac{k}{F}\right)^{m}\right] \\
& \left.\cdot(-m \delta)\left(\frac{k}{F}\right)^{m-1} \frac{1}{F} \frac{\partial k}{\partial \varepsilon_{1 t}}\right|_{\varepsilon_{1 p}}=0 .
\end{aligned}
$$

And then, the statistical parameters can be described by

$$
\begin{aligned}
& m=\frac{k E_{T} H_{3}}{\left.H_{2}\left[H_{3}+(\delta-1) H_{2}\right]\left(\partial k / \partial \varepsilon_{1 t}\right)\right|_{\varepsilon_{1 p}} \ln \left(\delta H_{2} / H_{3}+(\delta-1) H_{2}\right)} \\
& F=\frac{k}{\left[\ln \left(\delta H_{2} / H_{3}+(\delta-1) H_{2}\right)\right]^{1 / m}} .
\end{aligned}
$$

Where $H_{3}=\sigma_{1 \mathrm{p}}+(1-2 \mu)\left(\sigma_{3}-p_{\mathrm{w}}\right)$, and $\left.\left(\partial k / \partial \varepsilon_{1 t}\right)\right|_{\varepsilon_{1 p}}=$ $\left(\sin \varphi / \sqrt{9+3 \sin ^{2} \varphi}\right)\left(\left(\sigma_{1 p}+3 \sigma_{3}-3 p_{w}\right) E_{T} / \sigma_{1 p}+(1-2 \mu)\left(\sigma_{3}\right.\right.$ $\left.\left.-p_{w}\right)\right)+\left(\sigma_{1 p} E_{T} / \sqrt{3}\left[\sigma_{1 p}+(1-2 \mu)\left(\sigma_{3}-p_{w}\right)\right]\right)$.

Finally, parameters $\mathrm{A}$ and $\mathrm{B}$ have been determined considering the continuity of the first-order derivative as follows [28-34]:

$$
\left.\begin{array}{l}
A=\frac{Z \varepsilon_{D}-R}{\varepsilon_{D}^{2}} \\
B=\frac{2 R-Z \varepsilon_{D}}{\varepsilon_{D}}
\end{array}\right\} .
$$

In which, $H_{4}=E_{T} \varepsilon_{D}+(1-2 \mu)\left(\sigma_{3}-p_{w}\right), H_{4}\{1-\delta+\delta$ $\exp \left\{-\left[(k / F)^{m}\right]\right\}+(2 \mu-1)\left(\sigma_{3}-p_{w}\right)=R$, and $\left(\partial \sigma_{1 t} / \partial \varepsilon_{1 t}\right) \mid$ $\varepsilon_{D}=E_{T}\left\{1-\delta+\delta \exp \left[-(k / F)^{m}\right]\right\}+H_{2} \exp \left[-(k / F)^{m}\right](-m$ $\delta)\left.(k / F)^{m-1}(1 / F)\left(\partial k / \partial \varepsilon_{1 t}\right)\right|_{\varepsilon_{D}}=Z$.

5.3. The Permeability Evolution of the Heat-Treated Sandstone Based on the Mentioned Theory. Based on the mentioned theory and corresponding experiments, the curves about the damage vs. axial strain and damage vs. permeability of the heat-treated sandstones are plotted in Figure 14. It can be seen that the damage increases with increasing axial strain and the permeability variation is obviously related to the damage variation. As shown in Figure 14, it can be concluded from the evolution of the permeability and damage variable that the new cracks propagate slowly and corresponding damage also varies smoothly in the initial compressed stage because of small cracks density and no cracks coalescence, causing the cracks closure and the permeability decrease; however, the damage increases gradually, indicating that the damage variation can describe the cracks development and represent the permeability variation; once the damage changes quickly, the permeability will change abruptly. Furthermore, as for the descending stage after the peak stress, the aperture decreases, and the cracks slides under the axial loading condition, the seepage channels will be blocked causing the permeability decrease; however, the rock damage still increases, revealing the mechanism of the permeability evolution for the heat-treated sandstone.

In addition, increasing axial strain representing the cracks propagation can describe the permeability variation; however, the damage and corresponding permeability of the sandstones with different heated temperature are different, indicating that the temperature has important thermal influence on the rock damage and further permeability evolution. 


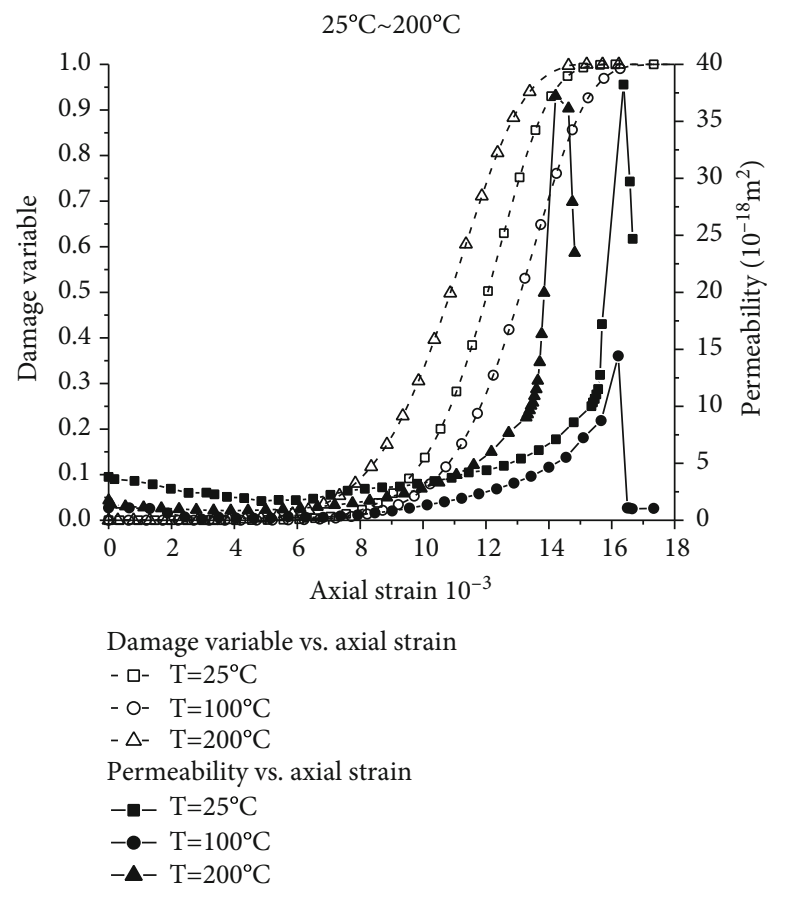

(a) $25^{\circ} \mathrm{C} \sim 200^{\circ} \mathrm{C}$

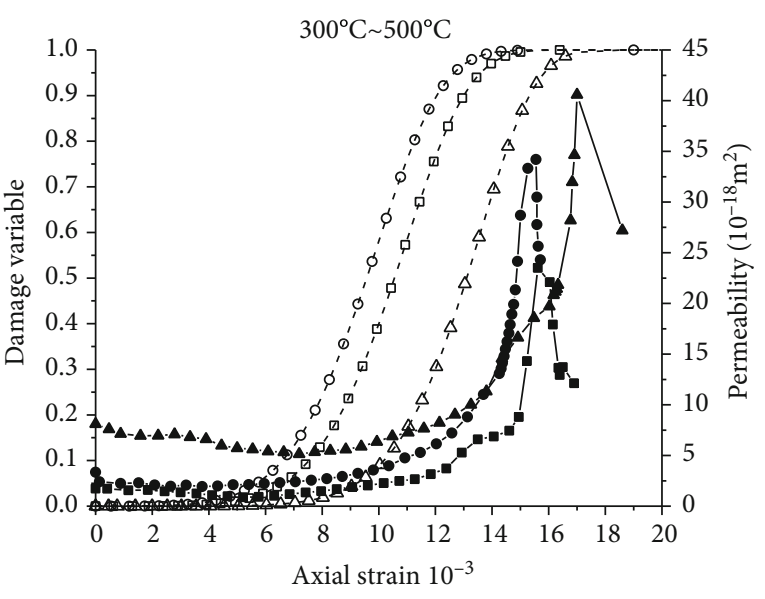

Damage variable vs. axial strain

- 口- $\mathrm{T}=300^{\circ} \mathrm{C}$

- o- $\mathrm{T}=400^{\circ} \mathrm{C}$

- $\triangle-\mathrm{T}=500^{\circ} \mathrm{C}$

Permeability vs. axial strain

- $-\mathrm{T}=300^{\circ} \mathrm{C}$

- $\mathrm{T}=400^{\circ} \mathrm{C}$

- $\boldsymbol{\Delta}-\mathrm{T}=500^{\circ} \mathrm{C}$

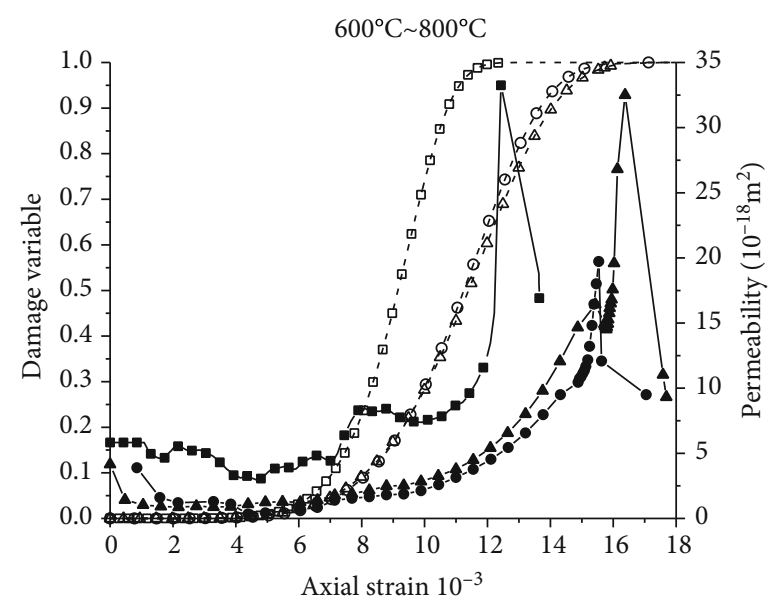

Damage variable vs. axial strain

- 口- $\mathrm{T}=600^{\circ} \mathrm{C}$

- o- $\mathrm{T}=700^{\circ} \mathrm{C}$

- $\triangle-\mathrm{T}=800^{\circ} \mathrm{C}$

Permeability vs. axial strain

- $\mathrm{T}=600^{\circ} \mathrm{C}$

$-\bullet \mathrm{T}=700^{\circ} \mathrm{C}$
$-\mathrm{T}=800^{\circ} \mathrm{C}$

(c) $600^{\circ} \mathrm{C} \sim 800^{\circ} \mathrm{C}$

FIGURE 14: Curves of the permeability and damage variable vs. axial strain of the heat-treated sandstones.

And for better describing the permeability of the heattreated sandstones [35-39], an expression representing the relationship of the permeability and the damage has been proposed,

$$
K=A_{1} \exp \left(\frac{D}{\lambda_{1}}\right)+A_{2} \exp \left(\frac{D}{\lambda_{2}}\right)+B
$$

Where $K$ is the permeability $\left(\mathrm{m}^{2}\right) ; D$ is the damage variable related to the heated temperature; $A_{1}, A_{2}, \lambda_{1}, \lambda_{2}$, and $B$ are fitting parameters based on the experimental data. For proving the rationality of the proposed Eq. (24), the fitting curves based on experimental data are plotted in Figure 15. It is noted from the curves that the permeability and damage in the ascending stage is in good agreement with the exponential function, and all the correlation coefficients are greater 


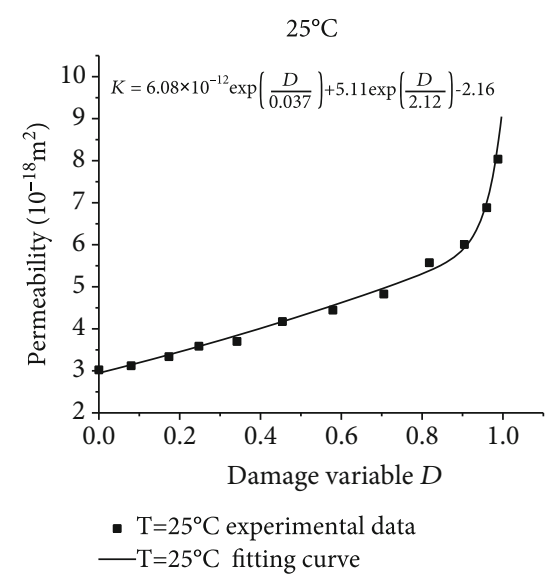

(a) $25^{\circ} \mathrm{C}$

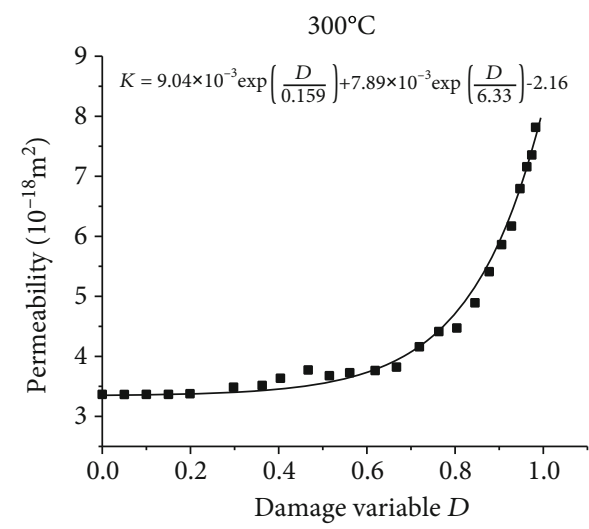

- $\mathrm{T}=300^{\circ} \mathrm{C}$ experimental data

- $\mathrm{T}=300^{\circ} \mathrm{C}$ fitting curve

(d) $300^{\circ} \mathrm{C}$

$600^{\circ} \mathrm{C}$

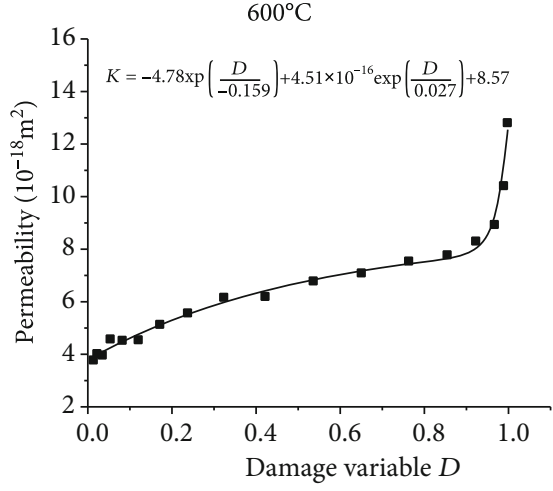

- $\mathrm{T}=600^{\circ} \mathrm{C}$ experimental data - $\mathrm{T}=600^{\circ} \mathrm{C}$ fitting curve

(g) $600^{\circ} \mathrm{C}$

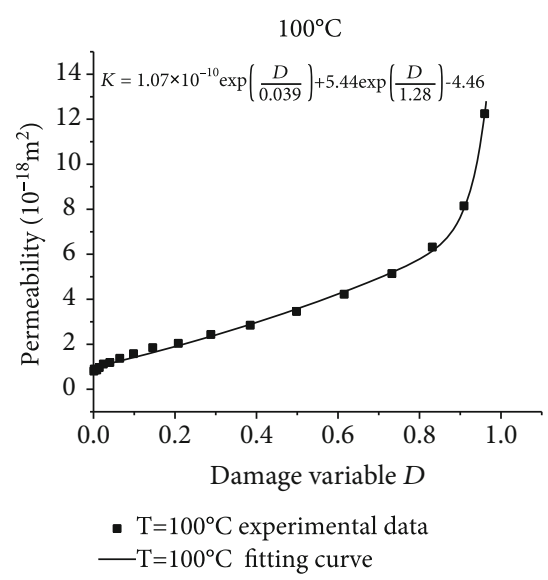

(b) $100^{\circ} \mathrm{C}$

$400^{\circ} \mathrm{C}$

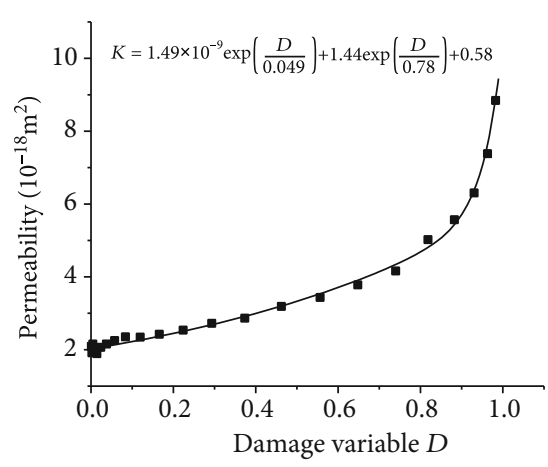

- $\mathrm{T}=400^{\circ} \mathrm{C}$ experimental data

- $\mathrm{T}=400^{\circ} \mathrm{C}$ fitting curve

(e) $400^{\circ} \mathrm{C}$

$700^{\circ} \mathrm{C}$

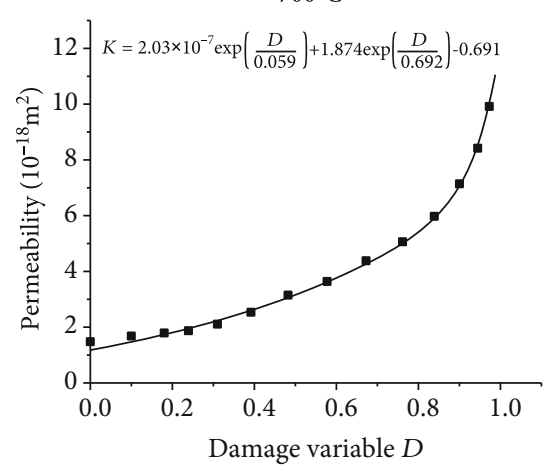

- $\mathrm{T}=700^{\circ} \mathrm{C}$ experimental data - $\mathrm{T}=700^{\circ} \mathrm{C}$ fitting curve

(h) $700^{\circ} \mathrm{C}$

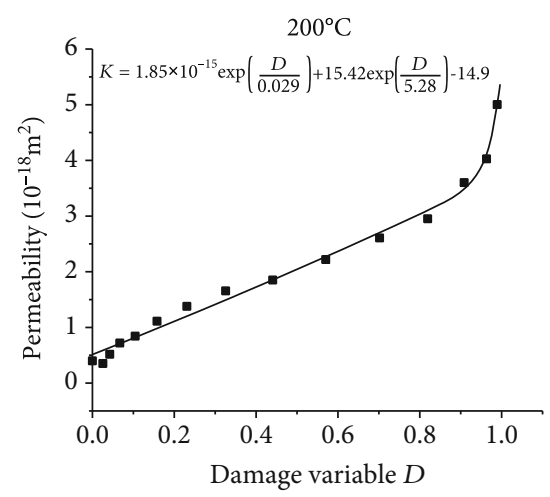

- $\mathrm{T}=200^{\circ} \mathrm{C}$ experimental data - $\mathrm{T}=200^{\circ} \mathrm{C}$ fitting curve

(c) $200^{\circ} \mathrm{C}$

$500^{\circ} \mathrm{C}$

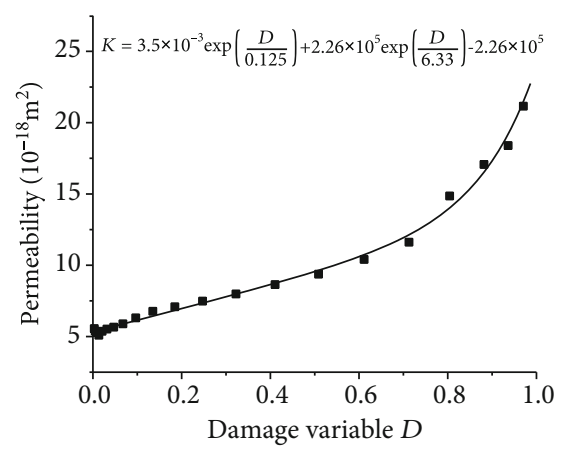

- $\mathrm{T}=500^{\circ} \mathrm{C}$ experimental data - $\mathrm{T}=500^{\circ} \mathrm{C}$ fitting curve

(f) $500^{\circ} \mathrm{C}$

$800^{\circ} \mathrm{C}$

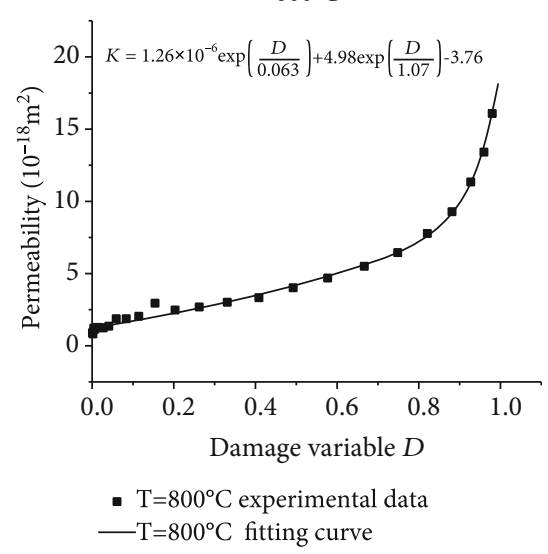

(i) $800^{\circ} \mathrm{C}$

FIGURE 15: The permeability evolution the damage variables of the heat-treated sandstone.

than 0.95 , indicating that the rock damage is the important index to represent the permeability characteristics of the heat-treated sandstones in the process of the gradual failure.

\section{Conclusions}

The heat-treated sandstones as a case study, the physical properties and mechanical properties are researched for the heat-treated sandstones, and also, the permeability evolution under triaxial loading conditions is investigated based on the experiments and theoretical analysis; thus, the corresponding permeability characteristics have been deeply obtained to reveal the evolution mechanism of the heat-treated sandstones considering the thermal effect by different heated temperature. The main conclusions obtained as follows: 
(1) The physical properties and the mechanical properties related to the heated temperature such as the mass, porosity, elastic modulus, and uniaxial compression strength have been obtained and the variations satisfy with the Boltzmann equation, indicating that the heat treatment causes obvious thermal effect on the sandstones properties

(2) The permeability of the heat-treated sandstones varies including the descending, smooth changing, stable increasing and abrupt ascending stage, and the characterized permeability have been obtained in range of different temperature, indicating that the heat treatment causes more effective flow paths

(3) The permeability and the crack volumetric strain has been deeply researched, indicating that loads causing different crack propagation resulting in different permeability evolution, and also the relationship between the permeability and crack volumetric strain reveals the important thermal effect on the permeability

(4) A constitutive model considering the thermalhydromechanical coupling effect has been proposed to reveal the relationship of the damage and the permeability, indicating that the damage can represent the evolution process of the permeability under the loading conditions considering the thermal effect by different heated temperature

\section{Data Availability}

The data in this manuscript is based on the lab experiments, and the analysis is based on the experimental data.

\section{Conflicts of Interest}

The authors declare that there are no conflicts of interest regarding the publication of this paper.

\section{Acknowledgments}

The research is financially supported by the National Natural Science Foundation of China No. 51779021 and the Fundamental Research Funds for the Central Universities No. 2020CDCGJ021. The authors declare that there is no conflict of interest regarding the publication of this paper.

\section{References}

[1] L. L. Guo, Y. B. Zhang, Y. J. Zhang, Z. W. Yu, and J. N. Zhang, "Experimental investigation of granite properties under different temperatures and pressures and numerical analysis of damage effect in enhanced geothermal system," Renewable Energy, vol. 126, pp. 107-125, 2018.

[2] B. Menendez, C. David, and M. Darot, "A study of the crack network in thermally and mechanically cracked granite samples using confocal scanning laser microscopy," Physics and Chemistry of the Earth, Part A: Solid Earth and Geodesy, vol. 24, no. 7, pp. 627-632, 1999.
[3] S. J. Du, H. Liu, H. T. Zhi, and H. H. Chen, "Testing study on mechanical properties of post-high-temperature granite," Chinese Journal of Rock Mechanics and Engineering, vol. 14, pp. 2359-2364, 2004.

[4] S. Chengdong, G. Wenbing, and L. Xiaoshuang, "Experimental research on mechanical properties of coarse sandstone after high temperature," Chinese Journal of Rock Mechanics and Engineering, no. 6, pp. 1162-1170, 2008.

[5] Z. Hongzhi, Y. Guangzhi, and L. Shen, "Experimental study on effect of temperature on sandstone damage," Chinese Journal of Rock Mechanics and Engineering, vol. 28, no. S1, pp. 27842791, 2009.

[6] Z. Lianying, X. Mao, and L. Tianzhen, "Experimental research on thermal damage properties of marble at high temperature," Journal of Mining \& Safety Engineering, vol. 27, no. 4, pp. 505$511,2010$.

[7] X. Xu, F. Gao, and X. Shen, "Research on mechanical characteristics and micropore structure of granite under high-temperature," Rock and Soil Mechanics, vol. 31, no. 6, pp. 17521760, 2010.

[8] L. Qingsen, S. Yang, and C. Guofei, "Strength and deformation properties of post-high-temperature joint sandstone," Journal of China Coal Society, vol. 39, no. 4, pp. 651-657, 2014.

[9] W. H. Sonerton and V. S. Gupta, "Role of fluxing agents in thermal alteration of sandstones," Journal of Petroleum Technology, vol. 17, no. 5, pp. 585-588, 1965.

[10] C. Shiwan, C. Yang, L. Pengjun, and W. Xiang, "Evolution of cracks and permeability of granites suffering from different thermal damages," Chinese Journal of Geotechnical Engineering, vol. 39, no. 8, pp. 1493-1500, 2017.

[11] S. Chaki, M. Takarli, and W. P. Agbodjan, "Influence of thermal damage on physical properties of a granite rock: porosity, permeability and ultrasonic wave evolutions," Construction \& Building Materials, vol. 22, no. 7, pp. 1456-1461, 2008.

[12] Y. L. Zhao, L. Y. Zhang, J. Liao, W. J. Wang, Q. Liu, and L. Tang, "Experimental study of fracture toughness and subcritical crack growth of three rocks under different environments," International Journal of Geomechanics, vol. 20, no. 8, article 04020128, 2020.

[13] Y. Zhao, C. L. Wang, and J. Bi, “Analysis of fractured rock permeability evolution under unloading conditions by the model of elastoplastic contact between rough surfaces," Rock Mechanics and Rock Engineering, 2020.

[14] S. Hu, C. Yifeng, and Z. Chuangbing, "Laboratory test and mesomchanical analysis of permeability variation of Beishan granite," Chinese Journal of Rock Mechanics and Engineering, vol. 11, pp. 2200-2209, 2014.

[15] L. Qiuzhuo and L. Ruide, "Study of evolution characteristics of microstructure and macroscopic physical properties of sandstone thermal damage," Tunnel construction, no. 1, pp. 7580, 2019.

[16] S. Y. Luo, B. Dou, H. Tian, J. Chen, P. Xiao, and S. T. Zhang, "Comparative experimental study on physical and mechanical properties of granite after natural cooling and under real-time high temperature," Earth Science Frontiers, vol. 27, no. 1, pp. 178-184, 2020.

[17] L. Zhang, X. Mao, M. Li, and B. Li, "Brittle-ductile transition of mudstone in coal measure rock strata under high temperature," International Journal of Geomechanics, vol. 20, 2020.

[18] D. C. Martin, The strength of massive Lac du Bonnet granite around underground openings [microform], [Ph.D. thesis], 
University of Manitoba, 1993, http://hdl.handle.net/1993/ 9785.

[19] L. Tianbin, M. Gao, C. Guoqing, and C. Ma, "A thermalmechanical-damage constitutive model for hard brittle rocks and its preliminary application," Chinese Journal of Geotechnical Engineering, vol. 39, no. 8, pp. 1477-1484, 2017.

[20] W. Wang, Z. Tian, Q. Zhu, X. H. Li, and W. Y. Xu-Chin, "Study of statistical damage constitutive model for rock considering pore water pressure," Chinese Journal of Rock Mechanics and Engineering, vol. 34, no. S2, pp. 3676-3682, 2015.

[21] J. Lemaitre, "A continuous damage mechanics model for ductile fracture," Journal of Engineering Materials and Technology, vol. 107, no. 1, pp. 83-89, 1985.

[22] Z. He, Z. Zhu, and R. Huaining, "A statistical constitutive damage model for rock under water pressure," Journal of Yangtze River Scientific Research Institute, vol. 36, no. 6, pp. 54-59, 2019.

[23] Y. Zhao, P. He, Y. Zhang, and C. Wang, "A new criterion for a toughness-dominated hydraulic fracture crossing a natural frictional interface," Rock Mechanics and Rock Engineering, vol. 52, no. 8, pp. 2617-2629, 2019.

[24] S. Chen, C. S. Qiao, Q. Ye, and K. M. Ullah, "Study on three dimensional damage constitutive modified model of rock under two kinds of distribution functions," Industrial construcion, vol. 47, no. S, pp. 1-7, 2017.

[25] Y. Zhao, L. Zhang, W. Wang, Q. Liu, L. Tang, and G. Cheng, "Experimental study on shear behavior and a revised shear strength model for infilled rock joints," International Journal of Geomechanics, vol. 20, no. 9, article 04020141, 2020.

[26] K. Peng, J. Zhou, Q. Zou, Y. Zhang, and G. Tan, “Deformation characteristics and failure modes of sandstones under discontinuous multi-level cyclic loads," Powder Technology, vol. 373, pp. 599-613, 2020.

[27] X. S. Liu, M. Li, M. Xu, and Z. Y. Kang, "Permeability of the hydrated shale under cyclic loading and unloading conditions," Geofluids, vol. 2020, Article ID 8863249, 16 pages, 2020.

[28] Y. Zhao, C. L. Wang, Y. F. Zhang, and Q. Liu, "Experimental study of adsorption effects on shale permeability," Natural Resources Research, vol. 28, no. 4, pp. 1575-1586, 2019.

[29] Z. Zhu, J. Guosheng, and T. Hong, "Study on statistical thermal damage constitutive model of rock based on normal distribution," Journal of Central South University (Science and Technology), vol. 50, no. 6, pp. 1411-1418, 2019.

[30] G. Zhao, C. Chen, and H. Yan, "A thermal damage constitutive model for oil shale based on Weibull statistical theory," Mathematical Problems in Engineering, vol. 2019, Article ID 4932586, 11 pages, 2019.

[31] M. Xu, J. Annan, and S. Hongtao, “An elastoplastic damage constitutive rock model and its stress mapping algorithm based on Hoek-Brown criterion," Engineering Mechanics, vol. 37, no. 1, pp. 195-206, 2020.

[32] H. Tian, M. Ziegler, and T. Kempka, "Physical and mechanical behavior of claystone exposed to temperatures up to $1000^{\circ} \mathrm{C}$," International Journal of Rock Mechanics and Mining Sciences, vol. 70, pp. 144-153, 2014.

[33] L. Liu, H. Ji, D. Elsworth, S. Zhi, X. Lv, and T. Wang, "Dualdamage constitutive model to define thermal damage in rock," International Journal of Rock Mechanics and Mining Sciences, vol. 126, article 104185, 2020.
[34] G. Wu, W. Chen, C. Rong, S. Jia, and Y. Dai, "Elastoplastic damage evolution constitutive model of saturated rock with respect to volumetric strain in rock and its engineering application," Tunnelling and Underground Space Technology, vol. 97, article 103284, 2020.

[35] X. S. Liu, M. Xu, and K. Wang, "Mechanism of permeability evolution for reservoir sandstone with different physical properties," Geofluids, vol. 2018, Article ID 5327895, 16 pages, 2018.

[36] T. He and C. Yaxian, "Regularity of permeability evolution of rock after high temperature," Journal of Yangtze River Scientific Research Institute, vol. 35, no. 11, pp. 107-111+116, 2018.

[37] J. Peihua, Y. Hu, and S. Jixi, "Study on pore structure and permeability of granite subjected to heating and water quenching," Taiyuan University of Technology, vol. 50, no. 4, pp. 478-484, 2019.

[38] W. Yin, Y. Zhao, and Z. Feng, "Experimental research on the permeability of fractured-subsequently-filled granite under high temperature-high pressure and the application to $\mathrm{Hdr}$ geothermal mining," Renewable Energy, vol. 153, pp. 499508, 2020.

[39] S. Q. Yang, P. Xu, Y. B. Li, and Y. H. Huang, "Experimental investigation on triaxial mechanical and permeability behavior of sandstone after exposure to different high temperature treatments," Geothermics, vol. 69, pp. 93-109, 2017. 